\title{
The history, relevance and applications of the periodic system in geochemistry
}

\author{
Derek Vance ${ }^{1 *}$ and Susan H. Little ${ }^{2}$
}

${ }^{1}$ Institute of Geochemistry and Petrology, Department of Earth Sciences, ETH Zürich, Clausiusstrasse 25, 8092 Zürich.

${ }^{2}$ Department of Earth Science and Engineering, Imperial College London, South Kensington Campus, Exhibition Road, London, SW7 2AZ, UK.

Present address: Department of Earth Sciences, University College London, London, UK.

*Corresponding author: derek.vance@erdw.ethz.ch; phone +41 44632 6881; fax +41 446321376.

Submitted to: Michael Mingos (ed)

Issue of Structure and Bonding on: The Periodic Table - how it has guided chemists for 150 years

Words in main text: 15538

Figures: 14

References cited: 182 


\section{Abstract}

Geochemistry is a discipline in the Earth Sciences concerned with understanding the chemistry of the Earth, and what that chemistry tells us about the processes that control the formation and evolution of Earth materials and the planet itself. The periodic table and the periodic law, as developed by Mendeleev and others in the $19^{\text {th }}$ century, is as important in geochemistry as in other areas of chemistry. In fact, systemisation of the myriad of observations that geochemists make is perhaps even more important in this branch of chemistry, given the huge variability in the nature of Earth materials - from the Fe-rich core, through the silicate-dominated mantle and crust, to the volatile-rich ocean and atmosphere. This systemisation started in the $18^{\text {th }}$ century, when geochemistry did not yet exist as a separate pursuit in itself. Mineralogy, one of the disciplines that eventually became geochemistry, was central to the discovery of the elements, and $19^{\text {th }}$ century mineralogists played a key role in this endeavour. Early "geochemists" continued this systemisation effort into the $20^{\text {th }}$ century, particularly highlighted in the career of V.M. Goldschmidt. The focus of the modern discipline of geochemistry has moved well beyond classification, in order to invert the information held in the properties of elements across the periodic table and their distribution across Earth and planetary materials, to learn about the physicochemical processes that shaped the Earth and other planets, on all scales. We illustrate this approach with key examples, those rooted in the patterns inherent in the periodic law as well as those that exploit concepts that only became familiar after Mendeleev, such as stable and radiogenic isotopes.

\section{Keywords:}

Periodic table, Periodic law, Geochemistry, Element discovery, Element classification, Radiogenic isotopes, Stable isotopes

\section{Contents}

\section{Introduction}

2 The scope of geochemistry and the particular need for systematisation

3 Historical perspective

3.1 Mineralogy and the discovery of the elements before and during the $19^{\text {th }}$ century

3.2 The contribution to the development of the periodic system from a geologist

3.3 The periodic system, isotopy, and the origins of two important sub-disciplines in geochemistry

4 The periodic system in geochemistry and the Earth Sciences

4.1 Classifying Earth materials: Mendeleev, Goldschmidt and beyond

4.2 Understanding Earth processes: trace elements ratios, Mendeleev's eka-silicon and beyond

4.3 Understanding Earth processes: the rare earth series

4.4 Understanding Earth processes: the transition metals and their stable isotope systems

5 Concluding remarks

References

\section{Abbreviations}
a
annum
$\mathrm{Ma}$
$\mathrm{Ga}$
mega annum $\left(10^{6}\right.$ years $)$
BSE
giga annum $\left(10^{9}\right.$ years $)$
PTE
Bulk Silicate Earth
REE
Periodic Table of the Elements
IUPAC
Rare-earth element
International Union of Pure and Applied Chemistry 


\section{Introduction}

Geochemistry (see texts [1-3]), as the name suggests, straddles the fields of chemistry and geology: it seeks to use the concepts and tools of chemistry to understand the Earth, its present state and its evolution over its 4.6 Ga history. The discipline is closely allied to the adjacent fields of planetary chemistry - the Earth itself is a planet after all - and cosmochemistry (e.g. [4]), sciences that are mostly concerned with extra-terrestrial objects, including planets beyond earth, the stars where nucleosynthesis of the elements occurs, and the meteorites and comets that constitute extra-terrestrial messengers from within and outside our Solar System. All these inter-related disciplines use similar methodologies and instrumentation to achieve twin objectives: to systematise observations on the chemical makeup of naturally-occurring materials, and to use the systematics to understand the principle physicochemical processes that form those materials, now and in the past. An important, somewhat more recent, sub-discipline within geochemistry also bridges to biology: biogeochemistry seeks to understand interactions between the biosphere and the chemistry of their abiotic environment (e.g. [5]).

Most of this volume concerns itself with the relevance of the periodic table in various branches of chemistry. The purpose of this contribution is to illustrate the importance of periodic relationships to the subject of geochemistry. We start by outlining some characteristics of the discipline that make systematisation particularly important. We then provide a historical perspective, with a focus on the role played by earth scientists in the discovery of the elements and the efforts at classification and systematisation that characterised the $19^{\text {th }}$ century, leading ultimately to the periodic system we know today. Geochemistry emerged as a separate sub-discipline of the earth sciences only in the $20^{\text {th }}$ century, and only fully in the latter half of that century. However, an important branch of what eventually became geochemistry - mineralogy - played a significant role in both the discovery of the elements and in the development of the periodic system, prior to and during the $19^{\text {th }}$ century. Finally, and most importantly, we illustrate with some examples how geochemists look at, interact with, and seek to further develop, the periodic system today.

\section{The scope of geochemistry and the particular need for systematisation}

Geochemistry has to deal with complex natural materials, that often contain every element in the periodic table at some non-zero concentration. Two examples of this phenomenon are shown in Fig. 1 and Fig. 2.

Fig. 1 [3] depicts the periodic table as a histogram that shows the variation in elemental concentrations estimated for the bulk silicate Earth (BSE), that part of the planet that is made up of minerals, rocks and their molten products that are predominantly composed of oxides of silicon. Spatially, the silicate Earth is located in the outer solid crust and the underlying mantle, thus excluding the Fe-rich core and the outer fluid envelope (ocean and atmosphere). More than 99\% of the BSE is made up of just 6 elements: oxygen, magnesium, silicon, iron, aluminium and calcium (Fig. 1). Oxygen being by far and away the most abundant anion, geochemists today continue the pre-Mendeleevean habit of expressing major cation concentrations in percentages of the equivalent oxide.

Geochemists use the "major" element composition of material brought to the Earth's surface, for example by volcanism, to track the similarities and differences between large-scale aspects of the bulk composition of the Earth and that of other Solar System bodies (e.g. [6]). They use the same data to understand the large-scale chemical differentiation of the Earth powered by its internal heat - e.g., the separation of a metallic core (e.g. [7]) or the formation and preservation of the continental crust (e.g. [8]). The methods of equilibrium thermodynamics are used to understand the organisation of the major elements into different mineral phases as a function of temperature and pressure (e.g. $[9,10])$. But what Fig. 1 also amply demonstrates is that geochemists concern themselves with the remaining $<1 \%$, beyond the $99 \%$ of the "major" elements. Indeed, "minor" and particularly "trace" element geochemistry has been of great and lasting utility (see section 4 for more on this). For example, the trace element geochemistry (as well as the isotope geochemistry - see below) of melts of the Earth's mantle, delivered to the surface by volcanism, has helped to quantify chemical heterogeneity in a part of the Earth that cannot be directly sampled (e.g. [11]), given a theoretical and 
experimental understanding of the partitioning of these trace elements between melt and solid residue as a function of the ionic charge and radius of the element concerned, and at the pressures and temperatures at which the melts are produced and equilibrate with residual solid (e.g. [12]). The ultimate aim of such endeavours is to elucidate the physical structure of the Earth's interior and its dynamical evolution over the 4.6 Ga of Earth history (e.g. [13]).

Similarly, the chemistry of the fluid envelopes around the solid Earth are also dominated by a small number of abundant elements. The surface Earth chemical cycles of this set of major elements, that make up the atmosphere, the ocean, as well as the chemical sediments that precipitate from that ocean, can tell us fundamental things about how the Earth has evolved. The preponderance of Fe-rich chemical sediments in the first 2 billion years of Earth history tells us that the surface Earth was vastly more reducing than now (e.g. [1416]). The abundance of molecular $\mathrm{O}_{2}$ in the modern atmosphere is a more recent phenomenon, resulting from the advent of oxygenic photosynthesis and the ability of plants to use sunlight to split water in order to reduce oxidised carbon. Chemical sediments built from the reduced and oxidised forms of carbon help record variations in the operation of the carbon cycle in Earth history (e.g. [17]), and has implications for the evolution of the surface environment as controlled by the natural greenhouse gases based on molecules involving carbon.

Figure 2 shows the variability in the dissolved concentrations in seawater, of elements, from across the periodic table, and illustrates how marine geochemists have also gone beyond the abundant elements. This variability must be explained by the major processes controlling seawater chemistry (e.g. [19-21]). For example, the spatial homogeneity in aqueous concentrations of most alkali metals, alkaline earths and the halogens is controlled by their high solubility in water. This feature of these elements results in a huge pool in solution in the global oceans, one that, on the timescale on which the oceans physically mix, is not easily modified by spatially variable processes (e.g., delivery by sources to the oceans such as rivers, or hydrothermal fluids, removal from solution by uptake into living cells or sorption to particle surfaces). Such homogeneity stands in marked contrast to the variability in the abundances of biologically active elements. Phosphorous, nitrogen (in their bio-available forms, as $\mathrm{PO}_{4}{ }^{3-}$ and $\mathrm{NO}_{3}{ }^{-}$), and many transition metals are reduced to near zero concentrations in the sunlit upper ocean (photic zone), where photosynthesising algae need them for their metabolism (e.g. [18]). Oxygen, supplied to the surface ocean through equilibration with the atmosphere, often shows a minimum at mid-depth where it is removed by aerobic respiration of sinking dead algal organic matter photosynthesised in the photic zone above. Other elements that are not particularly biologically-active, like aluminium or the rare earth elements, show variability due to local sources and sinks, such as removal by sorption to particles and sedimentation or sources from particles at depth or from the sediment (e.g. [22]). Geochemists use the kinds of information that are encapsulated in Fig. 2 to, for example, quantify and understand the major geological sources and sinks to the seawater solution (e.g. chemical weathering of the continents, hydrothermalism, sedimentation), and to elucidate the rate and pattern of biological uptake and the physical ocean circulation. They do this for the modern ocean that can be directly sampled (see e.g., www.geotraces.org), and they do it for the past ocean using chemical sediments precipitated from the past ocean (e.g. [23]).

Thus, the complexity of natural materials provides multiple sources of information that allow geochemists to learn about how the Earth works. But it also presents difficulties, difficulties that make the systematisation that is inherent in the periodic system and variants thereof crucial. Geochemists do not deal with simple laboratory systems. As Figures 1 and 2 illustrate, natural materials, be they mineral phases, rocks, silicate melts, aqueous solutions, or samples of atmospheric gas and aerosol, are often complex mixtures of every element in the periodic table. Complexity in geochemistry arises in other ways too. Geochemists think on spatial scales that range from the sub-atomic to that of the whole Earth. Planetary chemistry and cosmochemistry are concerned with even bigger scales. They also think on timescales ranging from the fractions of a second on which some natural chemical reactions take place, to the multi-billion-year lifetime of the Earth and the Solar System.

The scope of geochemistry is thus very broad. Geochemists measure, using ever more sophisticated instrumentation and down to the nanometre scale, variations in the concentrations of trace elements that are present in Earth materials at the femtomolar level. This analytical approach is coupled to experimental simulations of Earth and Solar System materials under natural conditions, to understand the controls on their 
chemistry, including their trace element geochemistry, and extending to the extremely high pressures and temperatures pertaining to the interiors of Earth and other planets (e.g. [24]). The third approach is more theoretical: numerical simulations that extend in scale from ab initio quantum chemical calculations on the interactions between a small number of atoms, up to planetary-scale simulations of large-scale mass transfer governed by advection and diffusion but incorporating chemical reactions as well (e.g. [25,26]). Because the main processes, and the timescale of those processes, are different for the solid Earth versus the ocean or the atmosphere, geochemists tend to focus on one of them. Geochemists, too, often restrict themselves to particular parts of the periodic table. Geochemistry has also incorporated the principles and knowledge developed in organic chemistry (e.g. [27]). The geochemistry of the noble gases, a group of elements not considered by Mendeleev, is an important sub-discipline (e.g. [28]). The authors of this paper are currently particularly interested in what the geochemistry of the transition metals tells us about biological cycling in the modern and past oceans (e.g. [29.30]). Still others focus on the lanthanides - the rare earth elements - whose coherent behaviour in Earth materials has made them particularly useful (e.g. [31]). Another important sub-discipline of geochemistry in which the two authors of the current paper are particularly invested, is isotope geochemistry (e.g. [32]). This latter discipline, much younger than Mendeleev, has revolutionised both our understanding of the chronology of Earth evolution and many aspects of mass transfer processes around the current and past Earth.

The need to systematise all this information, and to then make use of the systematics to understand processes, has, obviously and as in every other aspect of chemistry, led to a deep engagement with the periodic system. As in Fig. 1, and as will be seen again later in this contribution, earth scientists have been particularly active in augmenting and refining the periodic table, with the aim of further systematising the complex information they have to deal with in natural materials.

\section{Historical perspective}

The entry under "History" in the Encyclopedia of Geochemistry [33] notes that the first use of the term "geochemistry" was in 1838 by Christian Friedrich Schönbein, a Swiss professor of chemistry and physics at Basel and the discoverer of ozone. However, it was only in the $20^{\text {th }}$ century that geochemistry became differentiated from chemistry and geology, to form its own discipline. It really only grew into the quantitative and technology-driven field we know today in the latter half of that century. Nevertheless, sub-fields of geology that eventually emerged into geochemistry contributed significantly to both the discovery of the elements in the $19^{\text {th }}$ century, and to the establishment of the periodic system. The discovery of radioactive and stable isotopes around the turn of the $20^{\text {th }}$ century had major implications for the periodic table whilst also giving geochemistry one of its most important tools today. The founders of the discipline - Victor Moritz Goldschmidt, Frank Wrigglesworth Clarke, Vladimir Vernadsky, Harold Urey and Claire Patterson prominent amongst them - built on this foundation in the first half of the $20^{\text {th }}$ century to launch geochemistry on the path to modernity. In this section we briefly review these historical developments before returning in detail, with some key examples, of the use and relevance of the periodic table in and to modern geochemistry in section 4.

\subsection{Mineralogy and the discovery of the elements before and during the $19^{\text {th }}$ century}

Approximately 16 elements were known in 1750, most of them since antiquity [34,35]. By the time Mendeleev and others were thinking about a system of classification in the 1860 s, the number that had been isolated and characterised had increased to around 60 . After 1870 , but before the discovery of radioactivity, an entirely new group, the noble gases, was added and many of the rare-earth elements were unequivocally separated. Lutetium, hafnium and rhenium were the only elements with at least one stable isotope to be added in the $20^{\text {th }}$ century. Other than the noble gases, few elements are found in their elemental form in nature, and only rarely as simple compounds. They all had to be isolated from natural substances - usually from minerals, in a few cases from natural waters or from the atmosphere. The 150 years between 1750 and 1900 saw a craze for the documentation and classification of the natural world, a craze that helped to drive the discovery of the new elements. Though the work of isolation and characterisation was a chemical task, mineralogists played an 
important role, particularly in the case of the metallic elements on the left of the periodic table. Sometimes, the chemist and the mineralogist were combined in a single person. Many chemists were amateur mineralogists but, in several cases, the chemists who did the analysis also had formal training, and even held a chair, in mineralogy. In other cases, the discoveries resulted from strange new minerals found by mineralogists, subsequently analysed by laboratory chemists.

In the late $18^{\text {th }}$ century, before the spurt of element discoveries that came about with the advent of electrochemical techniques, the isolation of elements was often done starting with the simplest naturallyoccurring minerals. Thus, nickel was discovered by the Swedish mineralogist and chemist Baron Axel Fredrik Cronstedt in 1751 [34], when trying to extract copper from a nickel arsenide (NiAs). Often the metals were extracted by smelting - heating the ore mineral with charcoal or another form of reduced carbon to reduce metals in naturally-occurring oxides, sulphides, arsenides etc. Molybdenum and tungsten were isolated from the minerals molybdenite and wolframite in the 1780s. Fausto de Elhuyar, one of the two brothers credited with the discovery of tungsten [36], studied and taught mineralogy in Spain between stints in charge of Spanish mines in Mexico. Similarly, uranium was first isolated by Martin Heinrich Klaproth in 1789 by first dissolving the mineral uraninite - then called pitchblende - in nitric acid followed by precipitation as an oxide with sodium hydroxide and reduction with charcoal [37]. The other long-lived actinide, thorium, was discovered in 1829 [34] after Jens Esmark, a Danish-Norwegian professor of mineralogy and geology in Oslo, sent a sample of the mineral thorite - $(\mathrm{Th}, \mathrm{U}) \mathrm{SiO}_{4}$ - to Jöns Jacob Berzelius (on whom more below).

Klaproth was a mineralogist as well as a professor of chemistry in Berlin. He also analysed emeralds and beryls (e.g. $\mathrm{Be}_{3} \mathrm{Al}_{2} \mathrm{Si}_{6} \mathrm{O}_{18}$ ) but failed to identify beryllium as a new element. Beryllium was eventually isolated in 1798 by chemist Louis-Nicolas Vauquelin [38], from minerals supplied by French priest, mineralogist, contributor to the development of the metric system and the "Father of Modern Crystallography" René Just Haüy [39]. In $1791 \mathrm{Klaproth}$ had also realised that the mineral rutile $\left(\mathrm{TiO}_{2}\right)$ contained a previously unknown element that he named titanium. Credit for the discovery of titanium, however, is given to the British clergyman and amateur geologist, William Gregor. Gregor, also in 1791, isolated titanium oxide from ilmenite $\left(\mathrm{FeTiO}_{3}\right)$ he had found in a Cornish stream [37].

The first decade of the 19th century saw a spate of element discoveries, including sodium and potassium by Humphrey Davy using the new methods of electrochemistry [35]. Klaproth figures here again, however, having discovered "potash", long used as a fertilizer, in the minerals leucite and lepidolite. The discovery of the heavier alkali metals rubidium and cesium had to wait until the 1860s, for Bunsen, Kirchoff and flame spectroscopy [34]. Cesium was discovered in a local mineral spring while the rubidium came from the mineral lepidolite, in which lithium is a major constituent. Lithium itself had been isolated from the mineral petalite $\left(\mathrm{LiAlSi}_{4} \mathrm{O}_{10}\right)$ decades earlier (1817) by Johan August Arfwedson, working in the laboratories of fellow Swede Jöns Jakob Berzelius [34]. Arfwedson held degrees in both law and mineralogy, while Berzelius's analysis and preparation of compounds of new elements was fostered by a strong interest in mineralogy. Both have minerals named after them (arfvedsonite, a sodic amphibole, and berzelianite, a copper selenide; [40]).

Davy also used the new electrochemical techniques to isolate the four alkaline earths beneath beryllium in the PTE: $\mathrm{Mg}, \mathrm{Ca}, \mathrm{Sr}$ and $\mathrm{Ba}$ [35]. The salts of $\mathrm{Mg}$ and $\mathrm{Ca}$ had, of course, been known from antiquity. Strontium is named after the Scottish village of Strontian, where it was discovered in the ores of the lead mines, and was initially named strontianite by Scottish chemist Thomas Charles Hope [41]. The mineral collector Friedrich Gabriel Sulzer, together with fellow German Johann Friedrich Blumenbach, had analysed the mineral in 1791 and also named the mineral $\left(\mathrm{SrCO}_{3}\right)$ strontianite, stating that it contained a new element, one that was distinct, for example, from the main constituent of the mineral witherite $\left(\mathrm{BaCO}_{3}\right)$. Witherite has been named after the English geologist, mineralogist, botanist and chemist William Withering [40], who found it in Cumberland, also in lead mines. These mineral names stuck. The elements were given their modern names by Davy when he isolated them in 1808 .

The first decade of the $19^{\text {th }}$ century also saw the separation of a number of platinum group elements $(\mathrm{Pd}, \mathrm{Rh}$, Os, Ir) by William Hyde Wollaston and Smithson Tennant [42]. The mineral wollastonite (a pyroxene with chemical formula $\mathrm{CaSiO}_{3}$ ) and the Wollaston Medal, the highest award granted by the Geological Society of London and made from palladium, are named after the former. Wollaston also contributed to a controversy 
concerning two elements, told in [43], that have become important in geochemistry. The element niobium ( $\mathrm{Nb})$ had been identified by English chemist Charles Hatchett in 1801. Hatchett had discovered niobium in the mineral columbite $(\mathrm{Fe}, \mathrm{Mn}) \mathrm{Nb}_{2} \mathrm{O}_{6}$ and had called it columbium. Tantalum (Ta), directly beneath it in the modern periodic table, was discovered in 1802 by Swedish chemist Anders Ekeberg, in the mineral tantalite $(\mathrm{Fe}, \mathrm{Mn}) \mathrm{Ta}_{2} \mathrm{O}_{6}$. In 1809 Wollaston, despite finding that densities of the two oxides isolated from the two minerals were very different, concluded that the new element that Hatchett had claimed was, in fact, just tantalum. Further confusion was introduced in 1846, when the German mineralogist and chemist Heinrich Rose argued not only that the two elements differed but suggested a third, pelopium. The differences between tantalum and niobium were finally demonstrated in the 1860 s by, among others, Christian Wilhelm Blomstrand and Jean Charles Galissard de Marignac. Blomstrand was a Swedish mineralogist and chemist while Marignac held the chairs of both mineralogy and chemistry at Geneva from 1845 to 1878 .

It is interesting to a modern geochemist that all this confusion arose from the minimal chemical differences between tantalum and niobium. The minerals columbite and tantalite are chemically and structurally identical, being a solid solution between $\mathrm{Nb}$ and $\mathrm{Ta}$ end-members. The similar behaviour of the two elements during igneous processes, with nearly identical ionic radius and the same charge, led to them being regarded as geochemical "identical twins" during partial melting of the Earth's mantle (e.g. [44-47]). Despite this, the $\mathrm{Nb} / \mathrm{Ta}$ ratios of the Earth's upper mantle (conventionally thought to be the solid residue remaining after extraction of a partial melt that became the continental crust) is different, at 15-16, from the continental crust, at 11-13. Moreover, these two reservoirs, formed by the chemical differentiation of the silicate Earth through partial melting, do not add up to the 17.4 of chondritic meteorites, often thought to represent the bulk Earth before differentiation into core, mantle and crust. These observations require a missing reservoir in the interior Earth and a process that fractionates $\mathrm{Nb}$ from $\mathrm{Ta}$, counter to the idea of their behaviour of geochemical twins. The missing reservoir may be the Earth's core [46] or a deeply subducted slab at the core-mantle boundary $[45,47]$ The process that fractionates $\mathrm{Nb}$ from Ta may be the preferential partitioning of $\mathrm{Nb}$ into the iron-rich core [46], or slightly different partitioning of the two elements between fluid and mineral phases formed in subduction zones. These hypotheses, though competing, illustrate the use in geochemistry of ratios of two elements whose behaviour is broadly very similar but whose partitioning under specific conditions identifies the importance of a particular process.

Swedes and Germans figure prominently in the history of element discovery in the $19^{\text {th }}$ century, and nowhere more than in the long and fascinating sequence of events that led to the lanthanide series on the modern periodic table. The rare earths, usually the lanthanides with scandium and yttrium, were a particularly tough nut to crack for the $19^{\text {th }}$ century chemists and mineralogists because the similarity of the chemical properties across the series made them difficult to separate unequivocally as distinct elements. Like $\mathrm{Nb}$ and $\mathrm{Ta}$, this is precisely why they have been of such utility in modern geochemistry (see section 4.3): they behave as a coherent group of elements but exhibit small differences one from the other, differences that help to identify and elucidate the operation of quite specific processes.

The story starts with the isolation of the oxide "yttria" in 1794, from the mineral ytterbite (later renamed gadolinite) that had been found in 1787 near the Swedish village of Ytterby by Carl Axel Arrhenius [48]. Arrhenius sent it to Johan Gadolin, a Finnish chemist and mineralogist, who separated the new oxide (then called an "earth") from it. The find was confirmed by Anders Gustaf Ekeberg in 1797 who named the new oxide, equivalent to the element yttrium. A few decades previously, in 1751 another new mineral, cerite, had been found by Cronstedt at Bastnäs in Sweden. Berzelius isolated a new oxide from it that he called ceria, in 1803, the same year that Klaproth discovered the same oxide [37,48]. In 1839 a third mineral came to light, samarskite, described by the German mineralogist Gustav Rose (brother of Heinrich - see above) from the southern Urals [49]. In truth, all these minerals, and the oxides that the early work separated, contained mixtures of the rare earth elements (cerite enriched in the light REE, ytterbite in Y and the middle REE). In the late 1830s and early 1840s, Carl Gustaf Mosander showed ceria to be a mixture of oxides, including lanthana and what he called didymia $[34,48]$. At the same time, he also separated yttria into yttria, terbia and erbia. The metals that formed these oxides were thus named lanthanum, didymium, yttrium, terbium and erbium. It took another 30 years, and the advent of flame spectroscopy, before Paul-Émile Lecoq de Boisbaudran identified samarium in samarskite (1879), with gadolinium being further separated from the same mineral a year later [48]. Boisbaudran also discovered dysprosium, and went on to isolate europium from 
samarium-gadolinium concentrates in 1892. Meanwhile, in 1885 Carl Auer von Welsbach further realised that didymium was comprised of two separate elements, praseodymium and neodymium [34,37].

The Swedish chemist, biologist, mineralogist and oceanographer, Per Teodor Cleve, who started his academic career as an assistant professor of mineralogy at Uppsala, discovered holmium and thulium in 1878 and 1879 while removing impurities from a sample of erbium oxide [37]. Significantly for this volume, he also proved that the newly discovered element scandium, isolated by Lars Fredrik Nilson from ytterbite in 1879, was the "eka-boron" predicted by Mendeleev [35]. Ytterbium was isolated from ytterbite by Marignac in 1878 [37]. In 1907, the French chemist Georges Urbain further separated Marignac's ytterbia into two components that he called neoytterbia and lutecia. Neoytterbia later became known as the element ytterbium, and lutecia became known as the element lutetium. Two other scientists, von Welsbach and the American Charles James, independently isolated these elements at about the same time. A precedence dispute between Urbain and Welsbach had to be settled by the Commission on Atomic Mass. This consisted of three people: rather unfairly Urbain himself, with the other two being Wilhelm Ostwald and Frank Wrigglesworth Clarke. Unsurprisingly, the Commission found in favour of Urbain [50]. Clarke was the chief chemist of the U.S. Geological Survey from 1883 until his retirement in 1925. He was a founder of the American Chemical Society and is generally regarded as one of the fathers of geochemistry [33]. The F.W. Clarke medal of the Geochemical Society is awarded annually to an outstanding early career scientist in the areas of geochemistry or cosmochemistry.

The final chapter in the $19^{\text {th }}$ century was played out with the discovery of the noble gases, entirely unanticipated by Mendeleev. The first evidence for helium had come from the Solar spectrum in 1868, via a yellow line with wavelength $587.49 \mathrm{~nm}$ - what became known as the $\mathrm{D}_{3}$ line [37]. An Italian geophysicist, Luigi Palmieri detected terrestrial helium for the first time in 1881, finding the $\mathrm{D}_{3}$ line in a sublimate from a recent eruption of Mount Vesuvius [51]. In 1895, Sir William Ramsay isolated helium from the mineral cleveite, a variety of uraninite ([37]. This mineral was named after Per Teodor Cleve (see above), who independently isolated helium in the same year [37]. Ramsay and co-workers famously did the rest except for radon, which became the fifth radioactive element discovered, in 1899 by Ernest Rutherford and Robert Owens. The danger from exposure to radon in mines is now well known. It is fascinating to note that Georg Agricola, whom White [33] credits with the first geochemical text, De re metallica (1556), recommended ventilation in mines to avoid a wasting disease called mala metallorum, identified as lung cancer in the $19^{\text {th }}$ century.

\subsection{The contribution to the development of the periodic system from a geologist}

Dimitri Ivanovich Mendeleev is rightly described as "the undisputed champion of the periodic system" [35]. Though, as Scerri [35] also discusses in detail, there were others before him who thought about a periodic arrangement of the elements, it was Mendeleev's version that had a lasting scientific impact. Amongst all the scientists who were thinking along similar lines, it was also Mendeleev who continued to work on the concept, to develop and refine it. Of the two others who are conventionally listed as co-formulators of the Periodic Table of the Elements - Lothar Meyer and de Chancourtois (e.g. [35, 52,53]) - the latter was actually a geologist, which merits some further comment in the context of the topic in hand. Alexandre Emile Béguyer de Chancourtois was a professor in "subterranean topography" from 1848, and then geology from 1846, at the Ecole de Mines in Paris. As with all representations of the periodic system before the concept of atomic number arose in the early $20^{\text {th }}$ century, de Canchourtois's system [35] used atomic weight as the organising principle. It was also a three-dimensional concept, with the elements arranged along a spiral (Fig. 3). Each turn of the screw or spiral returned one to an element with the same properties - e.g. an alkali metal-like group with $\mathrm{Li}$, $\mathrm{Na}, \mathrm{K}$ or an alkaline earth-like group with $\mathrm{Mg}, \mathrm{Ca},(\mathrm{Fe})$, Sr. Scerri [35] suggests that the name De Chancourtois gave to his system, the telluric screw, may have come from the fact that De Chancourtois was a geologist, and the Greek word tellos, for Earth. He also discusses the fact that this complex representation of the periodic system, and the lack of an accompanying diagram in the original paper, contributed to the lack of recognition for De Chancourtois.

\subsection{The periodic system, isotopy, and the origins of two important sub-disciplines in geochemistry}


Thompson's discovery of the electron in the 1890s eventually provided the physical key to chemical periodicity and led Niels Bohr and others to a modern atomic theory of periodicity and the quantum theory of the atom. The discovery of x-rays by William Röntgen in 1895, and that of radioactivity by Henri Becquerel a year later, both had huge impacts across many fields. Röntgen's X-rays provided chemists with a means to probe the structure of all matter, including minerals and other natural materials. Henry Moseley, in 1914, proposed the idea of atomic number based on regular changes in the frequency of the $\mathrm{K}_{\alpha}$ radiation emitted by elements in a row across the periodic table. In the 1920s, Victor Moritz Goldschmidt, conventionally regarded as another of the fathers of geochemistry ([33]; see section 4.1), used X-ray diffraction to measure the ionic radii of 67 elements. He went on to deduce relationships between radius, charge, atomic number and periodic group that became "Goldschmidt's rules" (section 4.1).

The discovery of radioactivity was also important for the periodic table, in that it led directly to the discovery of many new elements and the filling of many gaps. Thus, the discovery of polonium and radium in 1898 by Marie Curie [34] arose through the study of radioactivity in natural ores of uranium such as uraninite (pitchblende). But the discovery of radioactivity was epoch-making in geochemistry: it gave earth scientists a quantitative tool to establish the timescale for Earth processes. It eventually led to a robust age for the Earth itself [55], and the primacy of the long-held view of geologists that the Earth had to be billions of years old over that of physicists like Lord Kelvin, who argued for an age of 20-40 million years [56]. Similarly, the realisation by Thompson and Aston that most elements consisted of multiple stable isotopes cleared up some $19^{\text {th }}$ century confusions concerning atomic weight and its periodicity [35]. But also, through Harold Urey's theoretical demonstration in 1947 [57] that nuclear mass has consequences for chemical bonding and rates of chemical reaction, it gave geochemists a new tool to understand the temperatures of Earth processes in the past, and the rates and mechanisms of mass transfer around planet Earth. The twin discoveries of radioactivity and stable isotopy gave geochemistry two of its most important sub-disciplines, radiogenic and stable isotope geochemistry, disciplines that were to revolutionise many aspects of how we understand the Earth [33].

\section{The periodic system in geochemistry and the Earth Sciences}

Another of the "fathers" of modern geochemistry, Viktor Moritz Goldschmidt (1888-1947), defined the central problem of the discipline to be "the determination of the distribution of the elements in the materials of the Earth and the reasons for this distribution" (quoted in [1]). Goldschmidt was born in Zurich but moved to Oslo in 1911, where he became professor and director of the Mineralogical Institute [33]. Though he moved to Göttingen in 1929, he returned to Oslo in 1935. Goldschmidt was Jewish and had to leave Oslo again during World War II, seeking refuge in Sweden but returning again to Oslo in 1946. Today, the highest honour of the Geochemical Society, awarded annually for major achievements in geochemistry and cosmochemistry, is named for him. And it is awarded annually at the premier geochemistry conference, the Goldschmidt Conference, co-organised by the Geochemical Society and the European Association of Geochemistry and attended by around 4000 geochemists from across the globe.

Goldschmidt's work encompassed thermodynamics, and the use of the x-ray spectrograph, to investigate the details of element abundance in minerals [33]. He realised that REE with even atomic numbers are more abundant than those with odd, and that their atomic radii decreased with increasing atomic number across the series. The name he gave to this phenomenon - the lanthanide contraction - is still used in geochemistry today. Goldschmidt's work on the ionic radii of the elements in mineral structures (by 1925 he and his colleagues had measured these for 67 elements [33], led him to propose a way of looking at the potentially bewildering variability in elemental abundances in Earth materials that is based on relationships between ionic radius, ionic charge, atomic number and periodic group. This schema (see section 4.1), built on the basis of Mendeleev's periodic system, is known to every undergraduate student of geochemistry today as Goldschmidt's Rules of substitution, and the resultant classification of naturally-occurring elements as the Goldschmidt Classification.

Goldschmidt's definition of the central goal of geochemistry, while one that modern geochemists would certainly recognise and acknowledge, is also reflective of its time. Goldschmidt lived and worked at a time 
when, as has been noted previously, classification and systemisation was still an important scientific pursuit, especially in young disciplines like geochemistry. Today, we would argue that a more important objective of geochemistry is to use the systematics that we have learnt to probe the modern planet and its history: essentially to invert information on the chemical makeup of Earth and Solar System materials to retrieve the physicochemical processes that determined their formation and evolution. As noted in the introduction, a quantitative understanding of the controls on element distribution from experiments and theory (thermodynamics, ab initio methods) is an important string in this particular bow. In the following sections we seek to illustrate these twin aims, starting with the work of classification and systemisation, whose basis has to be Mendeleev's periodic system but which geochemists like Goldschmidt and others have taken further. But we then go on to illustrate how the systematic behaviour can be used to understand the natural world, not just to classify it: how large and small differences in the chemical properties of pairs of elements, of element series, of isotopes of an element, help us understand how the Earth and the Solar System got to where it is today.

\subsection{Classifying Earth materials: Mendeleev, Goldschmidt and beyond}

The bulk chemical composition of planet Earth as a whole is mainly controlled by two very large-scale cosmic and Solar System processes. First, the relative cosmic abundances of all the elements mainly reflect production in the Big Bang (hydrogen, helium and some lithium), in stellar nucleosynthesis (most elements heavier than helium), spallation reactions caused by the fragmentation of atomic nuclei via collision with highly energetic cosmic rays (important for lithium, beryllium and boron), and by radioactive decay (e.g. [4]). The chemical signature of this history of element synthesis is broadly reflected in the bulk composition of the Solar System (Fig. 4). It determines, for example, the overall decrease in abundance with increasing atomic number. It is also reflected in the contrast between the abundances of elements adjacent to each other in the Periodic Table that have even versus odd atomic numbers, due to the greater stability of nuclei with even numbers of protons in nucleosynthetic environments (e.g. [58]). Second, the bulk composition of the terrestrial planets is also controlled by processes occurring during planetary accretion. Obtaining estimates for the composition of the whole Earth is difficult (e.g. [7,59]). The Earth's internal heat engine has driven chemical differentiation throughout its history, beginning during planetary accretion. The result is that we have no single sample whose chemical analysis tells us the bulk Earth composition. Instead, geochemists need to integrate estimates for the iron-rich core, the silicate mantle and crust, and the volatile-rich fluid envelope. It is, however, clear that the bulk chemical composition of Earth, and indeed all the terrestrial planets, is significantly different from the bulk Solar System. Models of Solar System formation suggest strong temperature contrasts in time and space within the early solar nebula, leading to differences in time and space in the accretion of different elements to growing Solar System bodies due to different temperatures for condensation from the gaseous to the solid or liquid state (Fig. 5). As a result, the planets show a strong chemical zonation, with the four inner terrestrial planets being strongly depleted in volatile elements relative to both the Sun (Fig. 4) and the outer Solar System gas giants.

The way this bulk planetary composition is distributed amongst the different physical materials that make up the Earth is also one of the themes of geochemistry. Fig. 1 illustrated the great variability in the abundances of the elements in the silicate portion of the Earth. It is a matter of scientific common sense that geochemical reservoirs at the surface of the Earth other than the crust are very different in their chemical make-up. Thus, the atmosphere is dominated by nitrogen. The natural waters at the surface of the Earth, rivers, lakes and oceans (Fig. 2) represent often complex aqueous solutions in which concentrations of different elements range across more than 10 orders of magnitude. On the modern, oxidised surface Earth with abundant $\mathrm{O}_{2}$ in the atmosphere, many of the aqueous species that these elements form in solution involve oxygen. Much less accessible to direct scientific observation is the fact that a lot of the iron that the Earth must have, as well as some associated elements, is missing from the silicate Earth, implying an Fe-rich core on Earth and other Solar System bodies.

Mendeleev's periodic table can certainly be used to make general statements about how elements are organised into different materials on Earth, but geochemists have also devised extensions of Mendeleev's classification in order to deal with the immense variety and complexity of Earth materials. The first scientist to devise such a classification was Goldschmidt (Fig. 6; [60]), and his is still used as a qualitative tool today (e.g. Fig. 7). 
Goldschmidt's conceptual starting point was a hypothetical question: if the Earth had been at some time largely molten, how would different elements partition into different phases that form as such an Earth cooled. As discussed in Krauskopf and Bird [1] and White [3], there is a sound theoretical framework within which this question can be considered. For example, for a system with iron in excess, whether any given metal partitions into a silicate mineral or a metallic phase is, in theory, predictable from the relative free energies of formation of the relevant silicate versus that of iron. Goldschmidt himself (e.g. [61]) emphasised observations he had made using optical and X-ray spectroscopy of natural materials such as meteorites and igneous rocks, as well as the artificial products of the metallurgical industry: slag (silicate), metallic iron and its alloys, and matte (sulphide). On this basis he classified the elements that make up the minerals of the solid Earth as either lithophile (with an affinity for the minerals of "rocks"), siderophile (having an affinity for "iron") or chalcophile (literally "copper-loving" but as used here meaning an affinity for sulphide).

In terms of the periodic table (Fig. 7), the lithophile elements occur mostly, but certainly not exclusively, on the left of the periodic table. The key examples, the alkali metals and alkaline earths, are of course highly electropositive, highly reactive and have a strong affinity for oxygen. They form bonds that are dominantly ionic in character. In the mineral phases that make up the solid Earth, as realised by Goldschmidt, their ionic charge and radius are key to their behaviour and distribution. The alkali metals and alkaline earths are located in the larger octahedral sites in minerals, whereas the smaller lithophile elements further to the right, e.g. Al, $\mathrm{Si}$, occur in smaller tetrahedral sites. Elements lower down the alkali metal and alkaline earth groups have ionic radii that are larger than the octahedral sites in common silicate minerals so that their substitution causes lattice distortion. These elements are classed by igneous geochemists as "incompatible elements": in a system consisting of a mixture of melt and solid minerals these elements will not readily partition into the solid. This is also the case for smaller than ideal ions, e.g. Be. Further right in the periodic table, lithophile cations like $\mathrm{Zr}$, Hf and $\mathrm{Nb}$ are about the right size for silicate minerals but are more highly charged, so that their substitution into silicate minerals requires a coupled substitution to maintain charge balance. These "high-field strength" elements are also incompatible and, for example, zirconium becomes so enriched in igneous melts that it eventually forms its own mineral phases from late residual melts. Siderophile elements tend to be in the centre of the periodic table, mainly in groups 8-10. In his papers, Goldschmidt, as early as the 1920s, surmised that the scarcity in the Earth's crust of precious metals such as platinum and palladium arises because these elements would preferentially partition into a metallic iron phase so that they are now concentrated in the Earth's "nucleus" or core (see [61]). Chalcophiles occur in groups 11 and 12, and in the lower half of groups 13-16. It is now recognised that sulphide minerals that concentrate the chalcophile elements in the Earth's crust are mostly derived from an aqueous fluid rather than a melt.

Goldschmidt also defined two other element groups. The noble gases, on the extreme right of the periodic table, are the main constituents of the atmophiles. The noble gases are extremely volatile, are rare in solid Earth materials, and readily exsolve from silicate melts into a gaseous phase at low pressures. The atmophile group also includes more reactive elements, like nitrogen, carbon and hydrogen, that form compounds that also readily partition into a gas or aqueous phase. Goldschmidt included the halogens of group 17 in this category, while the modern version of the classification shown in Fig. 7 separates Goldschmidt's atmophiles into two groups that concentrate in a gas phase versus an aqueous fluid. Goldschmidt [61] defined a fifth grouping of elements, the biophiles, elements that are particularly important to the organic materials that make up the biosphere. In doing so he credited another early geochemist, the Russian Vladimir Ivanovich Vernadsky. Vernadsky (1863-1945) worked with Marie Curie, but is best known to modern geochemists as the father of biogeochemistry, the discipline that is concerned with the geochemical behaviour of biologically-important elements like carbon, hydrogen, oxygen, nitrogen, sulphur, phosphorous, and many transition metals. Yet another medal awarded at the annual Goldschmidt conference is named after Vernadsky. Implicit in the particular modern version of Goldschmidt's classification shown in Fig. 7 [60] is the point that was also made by Goldschmidt: the precise behaviour of an element depends on a number of variables - e.g. temperature, redox conditions - so that many elements can exhibit more than one category of behaviour.

Goldschmidt also considered how the processes he invokes that lead to the partitioning of different elements into different part of the Earth can be seen in terms of four stages in the planet's history: 


\begin{abstract}
"The first stage represents the partition according to affinity properties, which govern the partition between ionic, semi-metallic, and metallic phases, besides eventually a vapour phase, having come into action during the very early history of the earth. The second stage during processes of crystallisation represents the sifting and sorting of elements by crystals, according to particle size, especially ionic size, the order of introduction into fitting crystal lattices being controlled according to ionic charges. In the third stage of geochemical evolution, represented principally by the formation of sedimentary rocks, the quotient between ionic charge and ionic radius, the ionic potential, is a most important principle, governing the distribution of elements in the sediments. The fourth stage, controlled by the activities of living organisms, again furnishes remarkable concentrations and assemblages of elements, in part governed by special chemical valency properties, and in part directed by dominatingly physical principles.” Goldschmidt [61].
\end{abstract}

We have already alluded to the main processes in stages 1, 2 and 4 in the above statement. Stage 3 , the cycle of chemical weathering of rocks on the continents, the transfer of dissolved elements via rivers to the oceans, and the precipitation within the oceans of authigenic sedimentary minerals, is also controlled by key properties of elements as encapsulated in Goldschmidt's classification and the changing properties of elements across the periodic table. For example, the ionic bonds formed by the lithophiles at the left and right of the table are readily disrupted by water, such that these elements are very soluble in aqueous fluids and are present at high concentrations in seawater (e.g. Fig. 2). By contrast the highly-charged lithophile metals to the right of Groups I and II are often insoluble, in the case of the high field strength elements extremely insoluble. These latter are immobile in weathering, and tend to be concentrated in soils. In fact, they are often used as reference elements in assessing the degree to which chemical weathering processes have removed more soluble elements from a surface regolith developed on pristine rock (e.g. [62]). The small amounts of the less soluble cations present in surface Earth aqueous fluids often undergo hydrolysis to form simple complexes, the hydrolysis products of the smaller, highly charged cations losing protons to become oxyanions. Goldschmidt's representation of this ionic potential control on the form of elemental speciation in solution is shown in Fig. 8.

Fig. 9 shows another periodic table, with a much more recent classification [3,63] of the complexation behaviour of metals in complex natural aqueous solutions that contain anions or ligand-forming non-metals. The reader will note significant parallels between the element behaviour as depicted in Fig. 9 and their behaviour in solid Earth materials in Fig. 7. In Fig. 9 the elements of Groups 15-17 are complexing anions, or form complexing metal-binding ligands. Many of Goldschmidt's lithophile elements are classed as "hard" Ametals on Fig. 9. The ionic form of most lithophile metals has the noble gas electron configuration, high spherical symmetry and can be considered as "hard" spheres with point charges. In aqueous solution, these metals form complexes with fluoride or with ligands in which oxygen is the donor atom (e.g. $\mathrm{OH}^{-}, \mathrm{CO}_{3}{ }^{2-}, \mathrm{PO}_{4}{ }^{3-}$ , $\left.\mathrm{SO}_{4}{ }^{2-}\right)$. At the other extreme are the "soft" B-metals, corresponding approximately to the chalcophile elements, which have electron numbers corresponding to $\mathrm{Ni}^{0}, \mathrm{Pd}^{0}$ and $\mathrm{Pt}^{0}$. The ions of these metals have many valence electrons, their electron sheaths are highly polarizable and deformable, such that they are often described as "soft" metals. They form complexes with chloride and bromide, and with ligands containing S, $\mathrm{N}$ or I as donor atoms. The high solubility of zinc chloride complexes is crucial to the transport of $\mathrm{Zn}$ in crustal fluids that also often contain sulphide, with which $\mathrm{Zn}$ is extremely insoluble, and the formation of commercial ore deposits.

The transition metals are portrayed as a separate group in Fig. 9. characterised, of course, by a wide variety of possible valence states. As a result, they form an array of complexes in aqueous solution, of widely differing strengths. The increase in strength that occurs across the first row, from $\mathrm{Mn}$ to $\mathrm{Cu}$, is called the Irving-Williams series (Stumm and Morgan, 1996). In natural waters, very large fractions of the transition metal pool are bound in extremely strong (stability constants often in excess of $10^{12}$; [64]) organic complexes. In seawater $>99 \%$ of the $\mathrm{Cu}$ is bound in this way (e.g. [64]). Copper is often termed the "Goldilocks" metal of ocean biogeochemistry: $\mathrm{Cu}^{2+}$ is required by oceanic phytoplankton in very small amounts and it comes from the surrounding seawater solution, but $\mathrm{Cu}^{2+}$ is also toxic at levels above about $10^{-12} \mathrm{M}$ (e.g. [65]). Total $\mathrm{Cu}$ concentrations in seawater are much higher than this toxicity threshold $\left(10^{-9} \mathrm{M}\right.$ levels $)$, but nearly all of this is organically-bound in non-toxic form. Given that the binding organic ligands appear to derive from oceanic microbes themselves (e.g. [66]), this raises fascinating questions concerning the degree to which the oceanic microbial biosphere regulates its own environment, and even more important questions as to how such regulation of the entire external environment makes sense from the point of view of evolutionary biology. 
Finally in this section, we note that there has been a proposal in earth sciences for systematisation of element behaviour that goes beyond even the basic format of Mendeleev's table, in attempts to find better geometric ways to describe element behaviour in natural materials [67]. In its essentials, this more complex scheme seeks to meld the Mendeleev table with Goldschmidt's classification of the elements and the scheme shown in Fig. 9. In doing so, the approach emphasises the role of ionic charge in natural materials as an organising principle, with the result that, in this view, elements appear multiple times - e.g. C, N and some transition metals.

\subsection{Understanding Earth processes: trace elements ratios, Mendeleev's ekasilicon and beyond}

One of the key features of Mendeleev's first version of the periodic table, published in 1869, was that he left gaps where he predicted that elements would be discovered, whose atomic weights fit into his table and whose properties he predicted. One of Mendeleev's early and famous predictions, one of those that demonstrated the utility and power of the concept of periodicity, was that of the element germanium (Ge). What Mendeleev called ekasilicon (Es), lies directly below Si in the modern PTE, and was predicted by Mendeleev to have an atomic weight of 72 [35]. Germanium was duly discovered in 1886-1887 by Clemens Winkler (a chemist who started academic life in the Freiberg University of Mining and Technology), isolated from the rare mineral argyrodite [68]. He also determined the atomic weight to be 72.32 .

Germanium has been of some interest in geochemistry, with Goldschmidt [61] noting that its rarity in the Earth's crust is mirrored by its abundance in iron meteorites, leading him to class it a siderophile, and likely to be preferentially partitioned into the Earth's core. In fact, there are aspects of the distribution of germanium that match more than one of Goldschmidt's categories (Fig. 7). More interestingly in the context of this contribution, it is precisely because of its similarity to the more abundant element directly above it in both the modern and Mendeleev's periodic system that set germanium apart as an important tool in modern geochemistry. As noted in an earlier section, one of the difficulties geochemist's have to deal with is the chemical complexity of the natural materials around them. One common approach, in attempts to isolate and understand key processes is to focus specifically on a pair of elements, or a set of elements (like the REE, see section 4.3), that exhibit behaviour that is somewhat coherent but also different in ways that provide a crucial insight.

Germanium has outer electronic structure $3 \mathrm{~d}^{10}, 4 \mathrm{~s}^{2}, 4 \mathrm{p}^{2}$ and is mostly, like Si, quadrivalent in Earth and Solar System materials. Because of a nearly identical ionic radius to $\mathrm{Si}$, germanium's crustal geochemistry is dominated by its tendency to substitute for $\mathrm{Si}$ in mineral lattices, and in seawater they are dominated by the hydroxyacid species $\mathrm{Si}(\mathrm{OH})_{4}$ and $\mathrm{Ge}(\mathrm{OH})_{4}$ (e.g. [69]). One might think that all this would make the study of $\mathrm{Ge} / \mathrm{Si}$ ratios a tedious business but, like the $\mathrm{Nb} / \mathrm{Ta}$ ratios discussed earlier, it is exactly these strong similarities in properties that make the small differences so useful in understanding quite specific processes. The first study of germanium abundances in seawater [70] found that, though $\mathrm{Ge}$ is present at concentrations a million times lower than Si (picomolar, or parts per trillion), its abundance pattern follows that of Si extremely closely. A single group of marine eukaryotic microbes, the diatoms, undertake roughly $20 \%$ of all photosynthesis on Earth [71]. Because of this, and because diatoms build houses (called frustules) around their cells made of hydrated silica (opal) by extracting Si from the seawater solution, most photic zone seawater is extremely depleted in Si. The oceans are everywhere undersaturated in silica so that diatoms, while they are alive, must expend energy to precipitate their houses and stop them dissolving. In the deep ocean into which the dead cells sink, therefore, is a site of opal dissolution, and the deep oceans are relatively enriched in Si. In other words, $\mathrm{Si}$ behaves as a nutrient-like element. Germanium follows this behaviour exactly (Fig. 10). As Froelich and Andreae [70] note, this is:

"... a result that Mendeleev might have guessed when he predicted the occurrence and properties of element number 32 (which he called ekasilicon) based on his newly-discovered periodic law."

These authors go on to suggest that diatom opal in marine sediment should record the Ge/Si ratio of the dissolved pool of the oceans through time, a ratio that has been found to be around $0.73 \pm 0.03 \mu \mathrm{mol} / \mathrm{mol}[70,72]$ In an approach that is common in geochemistry, having established that $\mathrm{Ge} / \mathrm{Si}$ behave very similarly in this one important way (see $\mathrm{Nb} / \mathrm{Ta}$ in section 3.1 and on $\mathrm{Zr} / \mathrm{Hf}$ below) these and other workers have then sought 
environments where the ratio might be fractionated - i.e. the elements might be chemically decoupled from each other. The oceanic budget for Ge is summarised in Fig. 10 (modified after [69]), showing input and output fluxes to an oceanic dissolved pool that is assumed to be in steady-state. It turns out that chemical weathering of rocks leads to the preferential retention of Ge in secondary minerals formed in soils (e.g. [73]), so that the dissolved $\mathrm{Ge}$ and $\mathrm{Si}$ delivered to the oceans by rivers today has a $\mathrm{Ge} / \mathrm{Si}$ averaging around $0.54 \mu \mathrm{mol} / \mathrm{mol}$, lower than the value for rocks of the continents at about 1.5. How much lower depends on the intensity of chemical weathering [73]. Rivers deliver about $40 \%$ of the total Ge source to the oceans today. There are minor sources to the oceanic dissolved pool from wind-blown aerosols and low temperature alteration of basalts on the sea-floor (both $<5 \%$ ). At least $50 \%$ comes from submarine hydrothermal systems, where seawater drawn down into hot basalt near mid-ocean ridges reacts with the basalt such that the high temperature hydrothermal fluids that re-emerge (e.g. black smokers) have Ge/Si ratios of $11 \pm 3 \mu \mathrm{mol} / \mathrm{mol}$. So, in fact, there is, just in these data, a factor of almost 40 variation in the ekasilicon/silicon ratio of important surface Earth materials. Coupled to records of the chemistry of the past ocean, such variation that can, in principle, be used to understand drivers in changes in ocean chemistry through time (e.g. $[69,73,74])$. In modern geochemistry, the elemental abundances of $\mathrm{Ge}$ and $\mathrm{Si}$, and their ratio, has been augmented by the use of $\mathrm{Ge}$ and $\mathrm{Si}$ stable isotopes as well (see review in [69]).

Mendeleev also predicted an element that was a heavier analog to titanium (Ti) and zirconium (Zr) and with an atomic weight around 180. The discovery of the element hafnium (Hf) that eventually occupied that space took longer, and was a little more confused. Mendeleev originally placed lanthanum (La) in the position that eventually became Hf. Clarification of this issue had to wait until Henry Moseley established atomic number as a better organising principle for the periodic table than atomic weight [35]. His identification of the seven remaining gaps in the table, and the predicted properties of those elements, again led to attempts to isolate them from natural materials. The element Hf, atomic number 72, was isolated from the mineral zircon (a zirconium silicate with the chemical formula $\mathrm{Zr}_{2} \mathrm{SiO}_{4}$ ) by Coster and von Hevesy in 1923 [35]. It was the last element with stable isotopes to be discovered.

As members of the same group in the periodic table, $\mathrm{Ti}$, and particularly $\mathrm{Zr}$ and $\mathrm{Hf}$ show very strong geochemical similarities. Both $\mathrm{Zr}$ and $\mathrm{Hf}$ have a valence of +4 , and they have ionic radii in both 6-fold and 8fold co-ordination that are within a $2 \%$ of each other [3]. Despite these similarities, igneous geochemists have documented significant variations in $\mathrm{Zr} / \mathrm{Hf}$ ratios in the solid Earth, variations that can be used to probe particular processes. This approach is analogous to the discussion of $\mathrm{Ge} / \mathrm{Si}$ ratios above, and that of $\mathrm{Nb} / \mathrm{Ta}$ ratios in section 3.1 earlier. Indeed, $\mathrm{Nb} / \mathrm{Ta}$ and $\mathrm{Zr} / \mathrm{Hf}$ ratios, all high field strength elements (HFSE), are often considered together (e.g. [75]), with the objective of obtaining a deeper understanding both of which geochemical processes separate the two elements in these ratios, and of understanding the implications for the internal geochemical evolution of the Earth. Fig. 11 show a compilation of such data for various terrestrial silicate reservoirs, representing an example of this approach [75]. This particular study concludes that $\mathrm{Zr} / \mathrm{Hf}$ variations in ocean island basalts, surface manifestations of processes that begin with melting deep within the Earth, require a contribution from material recycled back into the mantle from the Earth's surface via plate tectonics, and specifically subduction zones. These authors also conclude, however, that this "ecologitic" source material does not have high $\mathrm{Nb} / \mathrm{Ta}$, that it thus cannot represent the complement to the remaining silicate Earth with its low $\mathrm{Nb} / \mathrm{Ta}$ relative to chondritic meteorites, and concur with Wade and Wood [46] that the $\mathrm{Nb}$ missing from the silicate Earth is in the Earth's core. At the other end of the temperature scale, the truly tiny concentrations of $\mathrm{Zr}, \mathrm{Hf}, \mathrm{Nb}$ and $\mathrm{Ta}$ (sub-picomolar in the case of $\mathrm{Hf}$ and $\mathrm{Ta}$ ) have been measured in seawater [76]. Unexpectedly, though $\mathrm{Nb} / \mathrm{Ta}$ ratios in seawater are close to the continental crust value (24 versus 22 $\mathrm{mol} / \mathrm{mol}), \mathrm{Zr} / \mathrm{Hf}$ ratios are almost an order of magnitude higher $(681$ versus $71 \mathrm{~mol} / \mathrm{mol})$, implying an important fractionation mechanism that has, as yet, not been identified.

The analysis of ratios of two elements from the same group of the periodic table to uncover what they tell us about the Earth is a long-established approach in geochemistry. In studies of the geochemistry of the oceans and of ocean sediments through time, it is particularly important for the alkaline earths. One of these, calcium, is a major constituent of the most important kind of chemical sediment precipitated from the ocean. Calcium carbonate $\left(\mathrm{CaCO}_{3}\right)$, in its two structural forms, calcite and aragonite, is precipitated almost everywhere in the modern and past ocean. Interestingly, though the surface oceans are over-saturated in $\mathrm{CaCO}_{3}$, these minerals are almost never formed without the intervention of biology, which is needed to overcome kinetic barriers to 
precipitation (e.g. [22]). Many organisms promote the precipitation of $\mathrm{CaCO}_{3}$ as houses, shells - the shells from which you extract the meat in a moules frites being a familiar example. There is a small industry in the measurement and interpretation of the trace element makeup, particularly alkaline earth elements, of biogenic calcium carbonate in the ocean (e.g. [77]). For example, the $\mathrm{Mg} / \mathrm{Ca}$ ratio of foraminifera (common marine protists that build shells, "tests", out of calcium carbonate) is controlled both by the $\mathrm{Mg} / \mathrm{Ca}$ ratio of the seawater from which these ions come, and by temperature. On geologically short timescales - perhaps $10^{5}$ years, $\mathrm{Mg} / \mathrm{Ca}$ in seawater is probably close to invariant given the huge reservoirs of $\mathrm{Mg}$ and $\mathrm{Ca}$ in the ocean and the slow input and output fluxes that could change this ratio e.g. [78]). Thus, $\mathrm{Mg} / \mathrm{Ca}$ ratios of foraminiferal tests preserved in ocean sediments have been used to quantify changes in ocean temperature in response to recent glaciation of the Earth (e.g. [79]). Similarly, Sr/Ca ratios of ancient corals are thought to be mainly controlled by temperature (e.g. [80]), and have been used to quantify sea surface temperature changes over the past millennium (e.g. [81]). $\mathrm{Ba} / \mathrm{Ca}$ ratios of marine carbonate, as well as the stable isotope composition of Ba, may be controlled both by the rate, intensity and pattern of past primary productivity $[82,83]$.

As one last example in this section, we consider ratios where the key characteristic is the difference rather than the similarity between the two elements concerned. The most prominent example comes from radiogenic isotope geochemistry (e.g. [32,84]). Virtually all we know about absolute timescales in earth science derives from the phenomenon of radioactivity. Thus, for example, one of the two minor isotopes of potassium, ${ }^{40} \mathrm{~K}$, undergoes decay by multiple mechanisms - one being electron capture to produce an isotope of argon, ${ }^{40} \mathrm{Ar}$. Radioactive decay is a probabilistic process, with the fraction of a population of parent nuclides that decays in unit time being a constant - the decay constant, denoted $\lambda$. The value of this decay constant for the decay of ${ }^{40} \mathrm{~K}$ by the electron capture pathway [85] is $0.5755 \times 10^{-10} \mathrm{a}^{-1}[86]$. The resultant half-life of ${ }^{40} \mathrm{~K}$ against electron capture will perhaps seem long to a chemist, but given an age of the Earth of $4.6 \mathrm{Ga}$, it is extremely useful in earth science. At its simplest, a measurement of the ${ }^{40} \mathrm{~K} /{ }^{40} \mathrm{Ar}$ ratio of a mineral in a rock gives the time since that mineral formed, provided the decay constant is known. Things are only this simple, however, if all the ${ }^{40} \mathrm{Ar}$ measured in the mineral today is radiogenic - in other words, derived from the decay of ${ }^{40} \mathrm{~K}$ - and produced in-situ since the mineral formed. If non-radiogenic ${ }^{40} \mathrm{Ar}$ is incorporated into the mineral lattice when it grew, or later, the age obtained from the measured ${ }^{40} \mathrm{~K} /{ }^{40} \mathrm{Ar}$ ratio will be too old. The extreme differences in the chemical behaviour of the two elements in the above example - one an alkali metal, the other a noble gas means that this condition is often met. Potassium readily partitions into a number of common minerals - micas, feldspar, amphiboles - whereas argon does not go into mineral lattices at all. The very minor amount of nonradiogenic argon in rocks and minerals gets there through sorption to surfaces. Thus, there is a huge advantage for the subject of geochronology in the different chemistries - the different groups of the periodic table - to which these two elements belong. Unfortunately, there are also disadvantages in this characteristic. Decay of ${ }^{40} \mathrm{~K}$ to ${ }^{40} \mathrm{Ar}$ places an atom of argon in a lattice site where it has no business to be. At the low temperatures of the earth surface the argon will remain in the mineral lattice, but if the mineral is heated by burial during the process of metamorphism it will diffuse out and be lost, leading to the derivation of an age from the ${ }^{40} \mathrm{~K} /{ }^{40} \mathrm{Ar}$ ratio that has nothing to do with initial mineral growth - though it can constrain the timing of the heating event (e.g. $[87,88])$.

Other geochronometers of the solid Earth afford qualitatively similar, but much less extreme, examples of these issues. Another commonly used geochronometer is the Rb-Sr system. One of the two isotopes of Rb, ${ }^{87} \mathrm{Rb}$, undergoes beta decay to ${ }^{87} \mathrm{Sr}$ with a half-life of $49.6 \mathrm{Ga}$ [89]. Rubidium is another alkali metal, $\mathrm{Sr}$ an alkaline earth. This, again, affords a big advantage for the use of this system in geochronology. Rubidium readily substitutes into the common rock-forming minerals that contain $\mathrm{K}$ as a major element, but these minerals contain only minor amounts of Sr. On the other hand, rock-forming minerals that contain $\mathrm{Ca}$ as a major element contain a lot of $\mathrm{Sr}$. The variation in $\mathrm{Rb} / \mathrm{Sr}$ ratio of a set of minerals formed at the same time in the same rock can be combined in an "isochron" approach to obtain an age, in an approach that circumvents the incorporation of minor amounts of Sr into Rb-rich minerals (e.g. [84]). As with K-Ar, however, this key advantage also comes with a disadvantage. Radiogenic $\mathrm{Sr}$ is lost from lattice sites designed for $\mathrm{K}$ or $\mathrm{Rb}$ when thermal energy becomes available in subsequent heating events to make diffusion rapid enough (e.g. [90]).

\subsection{Understanding Earth processes: the rare earth series}


The 'rare earth elements' (REE) or 'rare earth metals' (REM), as defined by IUPAC, include the first row of the two lines of elements at the bottom of the (short-form) periodic table, the 15 lanthanide rare earths, plus ytrrium (Y) and scandium (Sc). Despite the name, many of the REE are not particularly rare; for example, Ce is the $25^{\text {th }}$ most abundant element in Earth's upper continental crust, at $63 \mathrm{ppm}$ [91]. Nevertheless, the REE presented a major challenge to Mendeleev and other early pioneers of the periodic system. Mendeleev stated that their placement in his system represented one of the most difficult problems facing the periodic law. As William Crookes said:

"The rare earths perplex us in our researches, baffle us in our speculations and haunt is our very dreams. They stretch like an unknown sea before us, mocking, mystifying, and murmuring strange revelations and possibilities." (cited in Scerri [45], page 73)

One issue was that they were extremely difficult to separate chemically one from the other, as described in section 3.1 - they appeared to differ only very slightly in atomic weight and properties. Today, the REE are sometimes categorised as inner transition metals. Three key features of their chemistry have shaped their utility in the earth sciences. First, their ionic radii decrease gradually and progressively with atomic number, from $\mathrm{La}^{3+}(115 \mathrm{pm})$ to $\mathrm{Lu}^{3+}(93 \mathrm{pm})$, the aforementioned 'lanthanide contraction' observed and coined by Goldschmidt. Second, most REE are found in the +3 valence state at a wide range of oxygen fugacities. The exceptions are cerium (Ce), which can occur in the +4 state, and europium (Eu), which can partly be in the +2 state in the low oxygen Earth interior. Third, many of the REE radiogenic isotopes with long half-lives: the ${ }^{138} \mathrm{La}^{-138} \mathrm{Ce},{ }^{147} \mathrm{Sm}-{ }^{143} \mathrm{Nd}$, and ${ }^{176} \mathrm{Lu}-{ }^{176} \mathrm{Hf}$ radiogenic isotope systems have all proved useful tools for dating.

In igneous processes the REE behave incompatibly, meaning that they exhibit a preference for the liquid rather than the solid phase during melting. Nevertheless, the extent of this incompatibility varies with ionic radius. The heaviest rare earths have small enough radii that they can substitute for e.g., $\mathrm{Al}^{3+}$ or $^{2}{ }^{2+}$ in garnet or plagioclase feldspar (and some other mineral phases) and can thus be retained in the crystalline residue (e.g. [92]). Hence, heavy REE are more compatible than the light REE, and light REE are typically enriched relative to heavy REE in the products of melting (magmas). In order to illustrate this systematic variability in behaviour, and to overcome the zigzag pattern of elemental abundance for odd and even atomic numbers (Fig. 4), REE patterns are usually illustrated in plots of relative abundance, by comparison to a normalising material - often their concentrations in chondritic meteorites (Fig. 12; [92]). REE patterns illustrate graphically the presence of light or heavy REE enrichments in a sample, and also allow identification of 'abundance anomalies' of $\mathrm{Eu}$ or $\mathrm{Ce}$, which can be interpreted in terms of the oxygen fugacity during formation and/or the presence of plagioclase during crystallisation (into which $\mathrm{Eu}^{2+}$ partitions effectively).

The systematic behaviour of REE during melting and crystallisation leads to their utility in the study of igneous processes (e.g. [96]). Thereafter, REE are highly insoluble and immobile during metamorphism, weathering and sedimentation. As a result, primary REE patterns are conserved during geological processing, a feature that has allowed their development as excellent source tracers in a variety of fields within the earth sciences. On a global scale, average REE patterns in clastic sedimentary rocks have been used to estimate the composition of Earth's upper continental crust [97]. Regional tectonic settings and depositional environments have been inferred using a variety of major and trace element discrimination diagrams, in which the REE feature prominently (e.g., [98,99]). More recently, characteristic REE ratios of different Asian dust sources have been used to reconstruct past atmospheric circulation patterns, offering a new approach to assess the strength of the palaeo-monsoon in Asia [100,101].

Despite their low solubility in aqueous solution, the REE in seawater have also proven useful tools in oceanography [102] and marine sedimentology [103]. Seawater has a negative Ce anomaly (Fig. 12) due its presence in the +4 oxidation state and subsequent precipitation from solution as $\mathrm{CeO}_{2}$, while Eu anomalies in seawater reflect hydrothermal or aeolian input [104,105] The distinct REE fingerprints of riverine, hydrothermal and aeolian inputs thus provide information about the magnitudes and locations of each of these fluxes. Though the REE are removed from seawater by sorption/scavenging onto particles, water mass mixing also plays an important role in their dissolved distributions [104]. Zheng et al. [106] deconvolve the relative impacts of biogeochemical cycling (primarily scavenging removal) and physical transport using a multi- 
parameter mixing model, finding that $>75 \%$ of the dissolved REE distribution in the deep Atlantic results from water mass mixing.

Section 4.2 introduced the utility of radioactivity and radiogenic isotopes in geochemistry. The rare-earth series contains one of these radioactive decay systems, one that has been of consistent and widespread utility in the earth sciences - the Sm-Nd system. The isotope of Sm, ${ }^{147} \mathrm{Sm}$, undergoes alpha decay to ${ }^{143} \mathrm{Nd}$, with a half-life of $106 \mathrm{Ga}$ (e.g. $[3,32,107])$. This process produces variations, over the $4.6 \mathrm{Ga}$ history of the Earth, in the ratio of ${ }^{143} \mathrm{Nd}$ to a stable and non-radiogenic isotope of $\mathrm{Nd},{ }^{144} \mathrm{Nd}$, that depend on the time-integrated $\mathrm{Sm} / \mathrm{Nd}$ ratio of the sample in question. Such variations in the ${ }^{143} \mathrm{Nd} /{ }^{144} \mathrm{Nd}$ ratio, given the long half-life of ${ }^{147} \mathrm{Sm}$, are of course small, but they can be of order $10^{3}$ greater than the precision attainable with modern mass spectrometers (e.g. [108]). The fact that $\mathrm{Sm}$ and $\mathrm{Nd}$ are very similar in ionic radius and other chemical properties (with only promethium ( $\mathrm{Pm}$ ) with no stable isotopes between them) results in both advantages and disadvantages for the $\mathrm{Sm}-\mathrm{Nd}$ chronometer. The disadvantage is that the $\mathrm{Sm} / \mathrm{Nd}$ ratio of Earth materials does not show a great degree of variability, making isochron ages derived from it less precise than, say, for the $\mathrm{Rb}$-Sr system. The silicate mineral garnet is one of the few minerals with high $\mathrm{Sm} / \mathrm{Nd}$ ratios, resulting in more rapid evolution of ${ }^{143} \mathrm{Nd} /{ }^{144} \mathrm{Nd}$ ratios, leading to the successful application of the Sm-Nd system in the geochronology of metamorphic rocks (e.g. [109-112]).

The above characteristic also comes with a big advantage: unlike the Rb-Sr system, for example, the Sm-Nd system is very difficult to disturb, the chronometer is difficult to reset. This particular feature has made the Sm-Nd system one of the most important chronometers, and tracers, of the large-scale differentiation of the Earth (e.g. [107, 113-116]). The Sm-Nd system is reset by mantle melting because the two elements have slightly different preferences for solid mantle minerals versus silicate melt, and partition themselves differently during the process of melting of the mantle, which is always "partial" and leaves behind a residue of solid unmelted material. But the lower temperature processes occurring near the surface of the Earth appear to redistribute Sm and Nd on a mineral grain scale, but not on larger scales. The extent to which the latter holds in detail, whether the processes of melting within the continental crust, or chemical weathering at the surface, fractionate $\mathrm{Sm}-\mathrm{Nd}$ and reset the isotope system, has been a much-debated topic (e.g. [117,118]), but it is certainly the case to a much lesser extent than other systems.

In simple terms, the continental crust underneath us today has formed continuously throughout Earth history, as a result of mantle melting and the gravitational ascent of the buoyant melts produced (e.g. [8]). The portion of the Earth's mantle - the residual "depleted" mantle - from which the melts that ultimately formed the continental crust were extracted is depleted in $\mathrm{Nd}$ and enriched in $\mathrm{Sm}$. The continental crust, by contrast, is enriched in Nd over $\mathrm{Sm}$. This not only produces contrasts in the $\mathrm{Sm} / \mathrm{Nd}$ ratio of these two large-scale Earth reservoirs, the differences in $\mathrm{Sm} / \mathrm{Nd}$ ratios leads, over the long term, to differences in the $\mathrm{Nd}$ isotope composition of the two reservoirs. In the late 1970s, shortly after the Sm-Nd system was first developed [107], this concept was utilised to investigate the timing of this large-scale geochemical process, and the mass balance between the two reservoirs - the residual Nd-depleted mantle and the Nd-enriched continental crust. The depleted mantle appears to be sampled today by melting at mid-ocean ridges to produce MORB (mid-ocean ridge basalts). The sediment load of large rivers, that sample very significant areas of the upper continental crust, were used as representative analyses of that upper continental crust. The $\mathrm{Sm}-\mathrm{Nd}$ and $\mathrm{Nd}$ isotopic mass balance between these two sets of samples, together with a quantitative understanding of the melt-solid partitioning behaviour of $\mathrm{Sm}$ and $\mathrm{Nd}$ during mantle melting, sets constraints on the mass fraction of the mantle that has been depleted by melting. Furthermore, the difference in the $\mathrm{Nd}$ isotope compositions of the two reservoirs sets a time constraint on the process of crust generation. The importance of this approach is perhaps reflected in the fact that different research groups around the world latched onto it nearly simultaneously [107, 113-116]. The overall result from the three groups was similar: that around $25-40 \%$ of the mantle has seen a melting event that resulted in the complementary reservoir of the continental crust, and that the average age of the continental crust is around $2.0 \mathrm{Ga}$. The suggestion that only a fraction of the mantle has undergone this melting process has profound implications for its physical structure and the vigour of convective processes within it. The average age of the continental crust, given that this process continues today, implies that it must extend back to the early stages of the Earth. 
Since this pioneering work the picture has become more nuanced, complex and less certain. The result outlined above is observation and model-dependent. There are uncertainties over whether the bulk Earth Sm-Nd characteristics, an important input to the calculations, can really be assumed to be similar to that measured in chondritic meteorites (e.g. $[119,120])$. It is now much clearer that a substantial portion of material that has been produced by melting of the mantle has been subducted back into the mantle (e.g. [121]). Constraints from geophysical imaging of the interior Earth suggest that it is very difficult to maintain distinct mantle reservoirs against large-scale forces that induce mixing, like convection and plate tectonics (e.g. [13]). Other tools have also been harnessed to investigate this problem. An important piece of evidence for a non-chondritic bulk Earth comes from studies of another REE-based isotope tool, the tiny variations in the amount of the isotope ${ }^{142} \mathrm{Nd}$ arising from very early decay of the now extinct ${ }^{146} \mathrm{Sm}$ isotope (e.g. $\left.[119,120]\right)$. The mineral zircon $\left(\mathrm{Zr}_{2} \mathrm{SiO}_{4}\right)$ is another precise and robust chronometer, incorporating large amounts of the actinide uranium and very little of the radioactive decay product of that element, $\mathrm{Pb}$. Temporal patterns of U-Pb ages from zircons in crustal rocks, allied to progress using Hf and oxygen isotopes to identify "juvenile" zircon that has crystallised in material recently extracted from the mantle is an approach that is setting new constraints on temporal patterns of crustal growth, including its episodic nature (e.g. [8, 122-124]).

Earlier we cited the use of REE patterns in seawater as a tracer of ocean circulation. The latter is an important process in redistributing heat and matter, including chemical elements, around the globe. In addition to being a tool for geochronology, the radiogenic isotope composition of $\mathrm{Nd}$ in seawater and sediments has also been developed as a widely used tracer of mass transfer in the modern and past oceans, both to reconstruct the palaeocean circulation and in sediment provenance studies $[125,126]$. As noted above, the average age of the continental crust appears to be 1.8-2 Ga, but the process of continental crust extraction from the mantle began early in Earth history (e.g. [8]) and continues today. Thus, different geological terrains have different ${ }^{143} \mathrm{Nd} /{ }^{144} \mathrm{Nd}$ ratios that reflect their different geological histories (Fig. 13), specifically the time spent in the depleted mantle with its high $\mathrm{Sm} / \mathrm{Nd}$ ratio versus that in the crust with a low one. The application of $\mathrm{Nd}$ isotopes as an oceanographic and paleoceananographic tracer exploits this (e.g. [127]), and the geographical differences that are imparted to seawater, and to the products of erosion (sediments).

The first direct measurements of $\mathrm{Nd}$ isotopes in seawater (reported as $\varepsilon_{\mathrm{Nd}}$, the deviation of the measured ${ }^{143} \mathrm{Nd} /{ }^{144} \mathrm{Nd}$ ratio from bulk Earth, 0.512638 , in parts per 10000 ) were made in the late $1970 \mathrm{~s}$ [128,129] and, along with indirect measurements from seawater precipitates, e.g., ferromanganese crusts, it quickly became clear that the different ocean basins have distinct Nd isotope compositions. Deep waters formed in the North Atlantic, surrounded by old, unradiogenic continents, have the most negative $\mathrm{Nd}$ isotope ratios $\left(\varepsilon_{\mathrm{Nd}} \sim-13\right)$ while those waters surrounded by the young volcanic rocks in the North Pacific have the highest ratios $\left(\varepsilon_{\mathrm{Nd}} \sim\right.$ -4 ), with intermediate $\varepsilon_{\mathrm{Nd}}$ values in the Southern and Indian Oceans. These observations suggested a residence time of $\mathrm{Nd}$ that is shorter than the ocean mixing time, leading to its utility as a tracer for water mass mixing (reviewed in $[125,126]$ ). Changes in the ocean circulation through time, as reconstructed using $\mathrm{Nd}$ isotopes (among other approaches), are thought to be one important factor in a changing climate on glacial-interglacial, and longer, timescales (e.g. [130]). Records of seawater $\mathrm{Nd}$ isotope ratios through time (from ferromanganese crusts and coatings, corals and fish teeth) have allowed reconstruction of the palaeocean circulation. Though the utility of such approaches is still clear, the modern picture here is also now more nuanced and complex (e.g. [131]). For example, the use of $\mathrm{Nd}$ isotopes as a conservative tracer requires that isotope signatures of water masses are not modified during passage through the ocean and via interaction with bottom sediments [132] and their pore waters (e.g. [133]). The extent to which this is the case is currently under debate and, in fact, the potential importance of such a process for many elements emerged from in-depth studies of $\mathrm{Nd}$ isotopes in the ocean (e.g. [134]).

In addition to the dissolved pool, the $\mathrm{Nd}$ isotope composition of the detrital fraction of an offshore sediment core reflects the source of the sediment that has been eroded from the continent into the sea, providing information about continental erosion patterns through time. For example, Cook et al. [135] and Wilson et al. [136] observe changes in detrital $\varepsilon_{\mathrm{Nd}}$ in sediment cores offshore Antarctica, which they attribute to the waxing and waning of the East Antarctic ice sheet on Pliocene (5.3-2.6 Ma) and even late Pleistocene (last $500 \mathrm{kyr}$ ) timescales. These sediment provenance studies have major implications for our understanding of ice sheet dynamics, and the likely response of Antarctica to climate warming; the Pliocene ( $\sim 3 \mathrm{Ma}$ ago $)$ is thought to have been the last time the Earth's atmosphere contained 400 ppmv $\mathrm{CO}_{2}$. 


\title{
4.4 Understanding Earth processes: the transition metals and their stable isotope systems
}

So far, we have introduced approaches that geochemists adopt and the kinds of information they can glean either from the elemental fractionation that occurs during geological or chemical processing (e.g., of rare earth elements), or from the stopwatches and dyes or tracers of geological processes, the radiogenic isotope systems. The third string in the geochemist's bow is stable isotopy, introduced in sections 3.3. Isotopes constitute, of course, another phenomenon that was unknown to Mendeleev, first coming to light through the work of Thompson and Aston in the early $20^{\text {th }}$ century, as noted earlier. Their application in geochemistry is founded on two seminal publications outlining the theoretical basis for stable isotope fractionation, published in 1947 $[57,137]$. These two studies correctly predicted that small variations in the chemical behaviour of different isotopes of an element (usually related to small differences in mass) would have enormous utility in "the mapping of low and medium temperature phenomena" [2]. Stable isotope fractionation can derive from kinetic or equilibrium effects. Simply put, kinetic isotope effects reflect the fact that light isotopes react more quickly than heavier ones, while at equilibrium, the stronger the bond, the greater its enrichment in heavy isotopes. Traditionally, stable isotope geochemistry focussed on the light elements of $\mathrm{H}, \mathrm{C}, \mathrm{N}, \mathrm{O}$ and $\mathrm{S}$, with $\mathrm{Li}$ and B added to this list in the 1980 s, following a few earlier studies (e.g. $[138,139])$. Thorough reviews of these topics are presented elsewhere [140-142]. The authors of the current paper are particularly interested in the more recent development of transition metal stable isotope systems as tracers, particularly in the past and present ocean, and it is here that we focus our attention in this section. This also gives us the opportunity to highlight another set of elements that gave Mendeleev some trouble in terms of his periodic system.

Transition metals (groups $3-12$ ) are generally characterized by partially filled d subshells (except for those of group 12, which have filled d subshells, but exhibit similar chemical behaviour to the other transition elements). Transition metal chemistry is complex, for several reasons. First, the geometry of the d-orbitals is highly directional. Second, in nature, many transition metals have two or more valence states. Third, transition metals have intermediate electronegativities, such that they can exhibit both ionic and covalent bonding. These complexities lead to difficulties in satisfactorily predicting the behaviour of the transition metals based solely on their position in the PTE. A geochemical textbook has noted:

\begin{abstract}
"It is a general rule, illustrated by these two sets of numbers and also by several alternative sets that have been proposed as a measure of electronegativity, that numbers can be made to express very nicely the chemical properties of elements at the ends of the periods in the periodic table .... but that unresolvable difficulties arise in trying to express the subtle and complicated relationships among the transition metals in the interior of the table" (Krauskopf and Bird [1], p. 119).
\end{abstract}

As recognised by Goldschmidt (Figs 6, 7), the transition metals have siderophile, lithophile and chalcophile characteristics. In the first row, Sc, Ti and V are lithophile. Overall, $\mathrm{Fe}, \mathrm{Co}$ and $\mathrm{Ni}$ are siderophile, though in the earth's crust where native $\mathrm{Fe}$ is rare they are lithophile. $\mathrm{Cu}$ and $\mathrm{Zn}$ are chalcophile. In terms of their behaviour in near-surface or surface Earth aqueous phases (Fig. 9), the transition metals are primarily B metals, forming complexes with chloride and bromide, and with ligands containing S, N or I as donor atoms. As also noted earlier, a crucial aspect of the oceanic chemistry of the transition metals is their affinity for organic complexing ligands.

The chemical properties of transition metals also lend them to a variety of biochemical functions. In living organisms, metalloproteins, which contain at least one metal ion, are involved in the transfer of electrons (e.g., blue copper proteins), in reactions involving small molecules such as $\mathrm{O}_{2}$ (e.g., Fe in haemoglobin), in Lewisacid catalysis (e.g., $\mathrm{Zn}$ in carbonic anhydrase), and in the generation of reactive organic radicals (e.g., Co in vitamin $\mathrm{B}_{12}$ ). In the earth sciences, the biological functions of transition metals has fuelled recent research into their abundance patterns and isotope systems as potential biosignatures, i.e. as direct evidence in sedimentary rocks of past life forms $[143,144]$. More broadly, the recognition that algal growth in large areas of the world oceans is limited by the availability of transition metal micronutrients, particularly Fe [145], led to interest in the sources, sinks and speciation of bio-essential metals in the ocean, and in how their biogeochemical cycles may have changed in the past. 
Early attempts to analyse transition metal stable isotope ratios were hindered by their high molecular weights and the resultant small magnitude of mass-dependent isotope fractionation. However, the advent of multiple collector inductively coupled plasma mass spectrometry (MC-ICP-MS) [146] enabled the precise and accurate analysis of stable isotope ratios of elements from across (and down) the periodic table, spawning the new field of 'non-traditional' stable isotope geochemistry [147]. To date, of the transition metals (for simplicity, the dblock elements of groups 3 - 12), the stable isotope systems of Ti, V, Cr, Fe, Ni, Cu, Zn, Mo, Pd, Ag, Cd, W, $\mathrm{Os}, \mathrm{Hg}$, and $\mathrm{Pt}$ are all in development as new tracers of geological and biogeochemical processes [148-154]. These stable isotope data are reported by comparison to a standard reference material (SRM) of known isotopic composition, in $\delta$-notation (variations of parts per thousand, \%):

$$
\delta^{\mathrm{x} / \mathrm{y}} \mathrm{Me}=\left(\frac{\left({ }^{\mathrm{x}} \mathrm{Me} /{ }^{\mathrm{y}} \mathrm{Me}\right)_{\text {sample }}}{\left({ }^{\mathrm{x} M e} /{ }^{\mathrm{y}} \mathrm{Me}\right)_{\mathrm{SRM}}}-1\right) \times 1000(\% 0)
$$

1023

1024

1025

1026

1027

1028

1029

1030

1031

1032

1033

1034

1035

1036

1037

1038

1039

1040

1041

1042

1043

1044

1045

1046

1047

1048

1049

1050

1051

1052

1053

1054

1055

1056

1057

1058

1059

1060

1061

1062

1063

1064

where ${ }^{\mathrm{x}} \mathrm{Me}$ and ${ }^{\mathrm{y}} \mathrm{Me}$ are the heavier and lighter stable isotope of the metal, respectively.

Of the transition metal isotope systems analysed to date, the Mo isotope system $\left(\delta^{98 / 95} \mathrm{Mo}\right)$ is one of the beststudied and most widely applied in palaeoceanography (reviewed in [155]). While several enzymes in the biological nitrogen cycle require Mo, the primary use of Mo in the geosciences has resulted from its geochemical behaviour, in particular, its redox-sensitive solubility in seawater. A trace element in the crust ( $\sim 1 \mathrm{ppm}$; [91]), Mo is the most abundant transition metal in oxygenated seawater, where it is primarily present as the soluble, unreactive, $\mathrm{MoO}_{4}{ }^{2-}$ oxyanion $(\sim 105 \mathrm{nM}$; [156]). Removal of Mo from an oxygenated water column occurs via slow scavenging to ferromanganese oxides, and is associated with light isotope fractionation; i.e. oxic sediments are enriched in isotopically light Mo [157,158]. By contrast, in anoxic and sulphidic (euxinic) waters sulphidised Mo species (ultimately $\mathrm{MoS}_{4}{ }^{2-}$ ) are removed from solution, leading to strong Mo enrichments in reducing sediments (e.g. [159,160]). In strongly euxinic environments the removal of Mo from the water column is near complete, or 'quantitative', thus no Mo isotope fractionation is recorded in the underlying sediments [157,161]. Overall, the Mo isotopic composition of seawater (today: $\sim 2.3 \%$ ) is determined by the isotopic composition of the inputs (today: $+0.7 \%$ ) and the balance of Mo removal to oxic $(-0.7 \%)$ and reducing $(\leq 2.3 \%)$ sedimentary sinks ([155] and references therein). Records of seawater $\delta^{98} \mathrm{Mo}$ from ancient euxinic sediments have therefore allowed geochemists to reconstruct secular trends in ocean redox, and to make links with the evolution of life through time (e.g. [162-164]).

The authors of the current chapter have focussed especially on the isotope systems of three elements adjacent to each other on the first row of the transition elements: $\mathrm{Zn}\left(\delta^{66 / 64} \mathrm{Zn}\right), \mathrm{Cu}\left(\delta^{65 / 63} \mathrm{Cu}\right)$ and $\mathrm{Ni}\left(\delta^{60 / 58} \mathrm{Ni}\right)$ $[30,165,166]$, and it is with a brief review of these three systems that we end this section. All three metals are essential for marine life and, it was initially expected, could provide insight into the biological cycling of carbon in the ancient ocean (e.g. [167]). Assuming a kinetic isotope effect during biological uptake, phytoplankton are expected to be enriched in light isotopes, as is observed for, e.g., carbon isotopes in plants. In this scenario, by mass balance, residual seawater will be isotopically heavy. Given an archive of seawater and knowledge of the magnitude of the kinetic isotope effect, the degree of nutrient utilisation can, in theory, be reconstructed - indeed, the isotopes of nitrogen (a macronutrient) have been developed as a palaeoceanographic tool in exactly this fashion (e.g. [168]). The question then is: could transition metal isotopes be used as a tracer of the pattern of activity of the past biosphere - e.g. primary productivity?

Culturing experiments with marine phytoplankton have borne out the prediction of light isotope fractionation during uptake to some extent (cf. e.g. [168,169]), but questions remain over the real drivers of isotope fractionation in culture (e.g., metal speciation versus kinetic controls) and the applicability of these experiments to the natural world. Characterising the natural world required a revolution in clean sampling and chemical separation methodologies, a revolution which has been spearheaded by the international GEOTRACES program (www.geotraces.org). This program has led to the production of tracer concentration and isotope data at unprecedented resolution in the modern ocean (Fig. 14; [171,172]). These new data are allowing marine biogeochemists to ground-truth the use of transition metal stable isotopes as palaeoceanographic tracers. 
Of the three metal isotope systems highlighted here, observations of $\mathrm{Ni}$ and its isotopes in seawater and sediments most closely match the predictions for the behaviour of a biologically cycled micronutrient element. The limited data for the oceanic dissolved pool of Ni isotopes is isotopically homogeneous at depth (at about $+1.3 \%$ ), with a small shift towards heavier values in the upper water column [173-175]. The latter is proposed to reflect a classic, albeit small, kinetic isotope effect during biological uptake. Meanwhile, organic-rich sediments record $\delta^{60} \mathrm{Ni}$ values very close to modern deep seawater in their inorganic material (at about $+1.2 \%$ ) and a fractionation imparted by biological uptake in the photic zone in an isolated organic fraction. Systematic relationships between $\mathrm{Ni}-\mathrm{TOC}-\delta^{60} \mathrm{Ni} \mathrm{OPF}_{-}-\delta^{13} \mathrm{C}$ indicate that $\mathrm{Ni}$ and $\mathrm{Ni}$ isotopes offer real potential as a palaeoproductivity tracer.

By contrast to $\mathrm{Ni}$, the isotope systems of $\mathrm{Cu}$ and $\mathrm{Zn}$ in seawater and sediments cannot be interpreted simply in terms of a kinetic isotope effect during biological uptake. Copper, the so-called 'Goldilocks metal', is bioessential, yet also toxic. As a result, phytoplankton produce organic ligands that bind the free $\mathrm{Cu}^{2+}$ species, reducing $\mathrm{Cu}^{2+}$ concentrations to levels that are 'just right' [64]. In fact, among the divalent transition metals, $\mathrm{Cu}$ forms the strongest complexes with organic ligands (the Irving-Williams series [176]: $\mathrm{Mn}^{2+}<\mathrm{Fe}^{2+}<\mathrm{Cd}^{2+}$ $\left.<\mathrm{Zn}^{2+}<\mathrm{Co}^{2+}<\mathrm{Ni}^{2+}<\mathrm{Cu}^{2+}\right)$. This feature of $\mathrm{Cu}$ chemistry exerts a first order control on its isotope geochemistry: strong bonds concentrate heavy isotopes. The heavy $\mathrm{Cu}$ isotopic composition of seawater (and rivers) has therefore been attributed to the preferential complexation of heavy $\mathrm{Cu}$ isotopes by organic ligands, while the lighter isotopic composition of sediments records the counterpart to this heavy dissolved pool $[177,178]$. For a geoscientist interested in the evolution of life on Earth, we might ask the question: when did organisms evolve to produce strong organic ligands, and why? The answer may lie in geological archives of seawater $\delta^{65} \mathrm{Cu}$.

Finally, isotopically heavy residual dissolved $\mathrm{Zn}$ in surface seawater, as predicted for a kinetic isotope effect, is only rarely observed in the modern ocean $[179,180]$. Another process or processes must be controlling upper water column $\mathrm{Zn}$ isotopes - and this is an area of active research. Nevertheless, because of its nutrient-like behaviour, nearly all the oceanic $\mathrm{Zn}$ inventory is in the deep ocean today. The deep ocean has a very homogeneous $\mathrm{Zn}$ isotopic composition $\left(\delta^{66} \mathrm{Zn} \sim 0.5 \%\right.$ ), which is isotopically heavy compared to the inputs (at $\sim 0.3 \%$ ) [166]. This seawater $\mathrm{Zn}$ isotope composition reflects the balance of $\mathrm{Zn}$ removal to oxic (isotopically heavy) and reducing (isotopically light) sedimentary sinks, in a manner similar to that previously described for Mo isotopes. In oxygenated settings, removal of $\mathrm{Zn}$ from seawater occurs by scavenging of isotopically heavy $\mathrm{Zn}$ to ferromanganese oxides [166,181]. The light isotope ratios of low oxygen, organic rich, sediments, must reflect light isotope fractionation, either during biological uptake (though we see little evidence for this in the water column), or during partial sequestration in to $\mathrm{Zn}$ sulphides in the sediment pile (e.g. [182]). The latter would strongly argue that seawater $\mathrm{Zn}$ isotopes offer a complimentary tool to Mo isotopes for the reconstruction of past oceanic redox.

\section{Concluding remarks}

This contribution has sought to highlight the immense contribution that Mendeleev and other $19^{\text {th }}$ century chemists and mineralogists have made to the modern field of geochemistry, by laying the basis for the periodic law in order to classify elements and understand their properties,. The $19^{\text {th }}$ century controversies in the discovery of the elements (e.g., Nb-Ta, the REE) heralded the approach by which geochemists use similarities and subtle differences between these elements as modern tools. The same applies to the predictions made by Mendeleev, including of eka-silicon or germanium as a heavier analogue of silicon, and the element beneath zirconium that was eventually confirmed to be hafnium. The discovery of many of the missing elements at the turn of the $20^{\text {th }}$ century led directly to the approach that revolutionised our understanding of the Earth - the ability to use radioactivity to date Earth materials and to finally establish the 4.6 Ga framework in which the Earth was formed and has evolved. Mendeleev and other early investigators of periodicity did not know about isotopes, stable, radioactive or radiogenic. This was another source of confusion, given that these scientists thought about periodicity in terms of atomic weights. Stable isotopy has, as with radiogenic isotopes, developed into an important observational tool in modern geochemistry. 
1119 The discipline of geochemistry continues to exploit Mendeleev's essential framework in understanding the 1120 Earth. The discipline has moved well beyond classification and systemisation, though this is still important. 1121 Modern geochemistry seeks to use the chemical properties of the elements, including their periodicity (as 1122 highlighted here using the way in which the alkaline earth series is used in ocean geochemistry). Rapid technological advances in the last few decades have opened up many further approaches, spanning the periodic table. Some of these we have not been able to deal with in detail (the noble gas group and their isotope systems, the platinum-group elements). The future is exciting and unpredictable, but the periodic table will continue to be the basis of all we do. 
1128 1. Krauskopf, KB, Bird, DK (1995) Introduction to geochemistry, $3^{\text {rd }}$ edn. Mc-Graw-Hill, Singapore.

1129 2. Albarede, F (2012) Geochemistry, and introduction, Cambridge University Press, Cambridge.

1130 3. White, WM (2013) Geochemistry. Wiley-Blackwell, Chichester.

1131 4. McSween, HY, Huss, GR (2010) Cosmochemistry. Cambridge University Press, Cambridge.

1132 5. Schlesinger, WH, Bernhardt, E (2013) Biogeochemistry: an analysis of global change. 3r edn. Academic Press.

1133 6. McDonough, WF, Sun, Ss (1995) The composition of the Earth. Chem Geol 120: 223-253.

1134 7. McDonough, WF (2014) Compositional model for the Earth's core. Treatise in Geochemistry 3: 559-577.

1135

1136

1137

1138

1139

1140

1141

1142

1143

1144

1145

1146

1147

1148

1149

1150

1151

1152

1153

1154

1155

1156

1157

1158

1159

1160

1161

1162

1163

1164

1165

1166

1167

1168

1169

1170

8. Hawkesworth, CJ, Cawood, PA, Dhuime, P, Kemp, AIS (2017) Earth's continental lithosphere through time. Ann Rev Earth Planet Sci 45: 169-188.

9. Holland, TJB, Green, ECR, Powell, R (2018) Melting of peridotites through to granites: a simple thermodynamic model in the system KNCFMASHTOCr. J Petrol 59: 881-900.

10. Connolly JAD (2017) A primer in Gibbs energy minimization for geophysicists. Petrology 25:526-534.

11. Hofmann, AW (2014) Sampling mantle heterogeneity through oceanic basalts: isotopes and trace elements. Treatise in Geochemistry 3: 67-101.

12. Wood, BJ, Blundy, JD (2014) Trace element partitioning: the influences of ionic radius, cation charge, pressure and temperature. Treatise in Geochemistry 3: 421-448.

13. Van Keken, PE, Ballentine, CJ, Hauri, EM (2014) Convective mixing in the Earth's mantle. Treatise in Geochemistry 3: 509-525.

14. Cloud, PE (1968). Atmospheric and hydrospheric evolution on the primitive earth. Science 160: 729-736.

15. Holland, HD (1984) The Chemical Evolution of the Ocean and Atmosphere. Princeton University Press, Princeton.

16. Farquhar, J, Zerkle, A, Bekker, A. (2014) Geologic and geochemical constraints on Earth's early atmosphere. Treatise on Geochemistry 6: 91-138.

17. Berner, RA (2004) The Phanerozoic carbon cycle. Oxford University Press, Oxford.

18. Sarmiento, JL, Gruber, N (2006) Ocean biogeochemical dynamics. Princeton University Press, Princeton.

19. Nozaki, Y (2001) Elemental distribution: overview. pp. 840-845 in Encyclopedia of Ocean Sciences, vol. 2. Steele, JH, Thorpe, SA, Turekian, KK, eds, Academic Press, London.

20. Broecker, WS, Peng, T-H (1982) Tracers in the Sea. Eldigio Press.

21. Roy-Barman, M, Jeandel, C (2016) Marine Geochemistry: ocean circulation, carbon cycle and climate change. Oxford University Press, Oxford.

22. Libes, SM (2009) An introduction to marine biogeochemistry, $2^{\text {nd }}$ edn. Academic Press, Amsterdam.

23. Lowenstein, TK, Kendall, B, Anbar, AD (2014) The geologic history of seawater. Treatise on Geochemistry 8, 569622 .

24. Holloway, JR, Wood, BJ (1988) Simulating the Earth: Experimental Geochemistry. Unwin Hyman, Boston.

25. Blanchard, M, Balan, E, Schauble, EA (2017) Equilibrium fractionation of non-traditional isotopes: a molecular modelling perspective. Rev Mineral 82: 27-63.

26. Vance, D, Little, SH, de Souza, GF, Khaitwala, SP, Lohan, MC, Middag, R (2017) Silicon and zinc biogeochemical cycles coupled through the Southern Ocean. Nature Geoscience 10: 202-206.

27. Kvenvolden, KA (2006) Organic geochemistry - a retrospective of its first 70 years. Org. Geochem. $37:$ 1-11.

28. Ozima, M, Podosek, FA (2002) Noble gas geochemistry, $2^{\text {nd }}$ edn. Cambridge University Press, Cambridge.

29. Little, SH, Vance, D Lyons, TW, McManus, J (2015) Controls on trace metal authigenic enrichment in reducing sediments: insights from modern oxygen-deficient settings. Amer J Sci 315: 77-119.

30. Moynier, F.,Vance, D, Fujii, T, Savage, P (2017) The isotope geochemistry of zinc and copper. Rev Mineral Petrol 82: 543-600. 
1171 31. Henderson, P (1984) Rare-earth element geochemistry. Elsevier, Amsterdam.

1172 32. White, WM (2015) Isotope geochemistry. Wiley, Hoboken.

1173 33. White, WM (2017) History of Geochemistry. In: White W. (ed.) Encyclopedia of Geochemistry. Encyclopedia of 1174 Earth Sciences Series. Springer, Cham.

1175 34. Weeks, MA, Leicester, HM (1956) Discovery of the elements. J. Chem. Education

1176 35. Scerri, ER (20007) The Periodic Table: its history and significance. Oxford University Press, Oxford.

1177 36. Eyles, JM (1956) Fausto de Elhuyar (1755-1833), a Spanish mining geologist. Geol Mag 93: 175-180.

1178 37. Emsley, J (2001) Nature's building blocks: and A to Z guide to the elements. Oxford University Press, Oxford.

1179 38. Vauquelin, L-N (1798) Aquamarine or beryl; and discovery of a new earth in this stone. Annales de Chimie 36: 1551180160.

1181 39. Kunz, GF (1918) The life and work of Haüy. Amer. Mineral. 3: 60-89.

1182 40. Anthony, JW Bideaux, RW, Bladh, KW, Nichols, MC (2019) (eds.) Handbook of Mineralogy, Mineralogical Society 1183 of America, Chantilly, VA 20151-1110, USA. http://www.handbookofmineralogy.org/.

1184 41. Murray, T (1993) Elementary Scots: the discovery of strontium. Scottish Med. J. 38, 188-189.

1185 42. Usselman, MC (2019) William Hyde Wollaston. Encyclopedia Brittanica. https://www.britannica.com

1186 43. Griffith, WP, Morris, PJT (2003) Charkes Hatchett FRS (1765-1847), chemist and discoverer of niobium. Notes

1187 Rec. R. Soc. Lond. 57: 299-316.

1188 44. Hofmann, AW (1988) Chemical differentiation of the Earth. Earth Planet Sci Lett 90: 297-314.

1189 45. Rudnick, RL, Barth, M, Horn, I, McDonough WF (2000) Rutile-bearing refractory eclogites: missing link between 1190 continents and depleted mantle. Science 287: 278-281.

1191 46. Wade, J, Wood, BJ (2001) The Earth's missing niobium may be in the core. Nature 409: 75-78.

1192 47. Tang, M, Lee, CTA, Chen, K, Erdman, M, Cotin, G Jiang, H (2019) Nb/Ta systematics in arc magma differentiation 1193 and the role of arclogites in continent formation. Nature Comms 019) 10:235, doi.org/10.1038/s41467-018-08198.

1194 48. Greenwood, NN, Earnshaw (1997) Chemistry of the Elements, $2^{\text {nd }}$ edn. Butterworth-Heinemann, Oxford.

1195 49. https://elements.vanderkrogt.net

1196 50. Clarke, FW, Ostwald, W, Thorpe, TE, Urbain G (1909) Report of the international committee on atomic weights, 1197 1909. J. Amer. Chem. Soc. 31, 1-6.

1198 51. Palmieri, L (1991) The line of helium appeared in a recently sublimated material from Vesuvius. Rendiconto 1199 Dell'Accademia delle Scienze Fisiche e Matematiche 20: 223.

1200 52. Farber, E (1969) The evolution of chemistry. Ronald Press, New York.

1201 53. Courtney, A (1999) A brief history of the development of the periodic table. 1202 http://www.wou.edu/las/physci/ch412/perhist.htm.

1203 54. Beguyer de Chancourtois, M (1862) Mémoire sur un classement naturel des corps simples ou radicaux appelé vis 1204 tellurique. Comptes Rendus 54: 757-761.

1205 55. Patterson, CC (1956) Age of meteorites and the Earth. Geochim. Cosmochimica Acta 10, 230-237.

1206 56. Burchfiel, JD (1990) Lord Kelvin and the age of the Earth. University of Chicago Press.

1207 57. Urey, HC (1947) The thermodynamics of isotopic substances. J Chem Soc 1947: 562-581.

1208 58. Palme, H, Lodders, K, Jones, A (2014) Solar System abundances of the elements. Treatise on Geochemistry 2: 15120936.

1210 59. Morgan, JW, Anders, E (1980) Chemical composition of Earth, Venus and Mercury. Proc Natl Acad Sci 77: 667312116677.

1212 60. Lee, CT (2016) Geochemical Classification of Elements. In: White W. (ed.) Encyclopedia of Geochemistry.

1213 Encyclopedia of Earth Sciences Series. Springer, Cham.

1214 61. Goldschmidt, VM (1937) The principles of distribution of chemical elements in minerals and rocks. The seventh 1215 Hugo Müller Lecture, delivered before the Chemical Society on March 17 $7^{\text {th }}$. Chem Soc 1140: 655-673. 
1216

1217

1218

1219

1220

1221

1222

1223

1224

1225

1226

1227

1228

1229

1230

1231

1232

1233

1234

1235

1236

1237

1238

1239

1240

1241

1242

1243

1244

1245

1246

1247

1248

1249

1250

1251

1252

1253

1254

1255

1256

1257

1258

1259

1260

1261
62. Vance, D et al. (2016) The behaviour of $\mathrm{Cu}$ and $\mathrm{Zn}$ isotopes during soil development: controls on the dissolved load of rivers. Chem Geol 445: 36-53.

63. Stumm, W, Morgan, JJ (1996) Aquatic chemistry: chemical equilibria and rates in natural waters, $3^{\text {rd }}$ edn. Wiley, New York.

64. Bruland, KW, Middag, R, Lohan, MC (2014) Controls of trace metals in seawater. Treatise on Geochemistry 8: 1951.

65. Brand, LE, Sunda, WG, Guillard, PRL (1986) Reduction in marine phytoplankton reproduction rates by copper and cadmium. J Exp Marine Biol Ecol 96: 225-250.

66. Moffett, JW, Brand, LE (1996) Production of strong, extracellular Cu chelators by marine cyanobacteria in response to Cu stress. Limnol Oceanogr 41: 388-395.

67. Retallack, LBR (2003) An earth scientist's periodic table of the elements and their ions. Geology 31: 737-740.

68. Winkler, C (1887) Germanium, Ge, ein neues, nichtmetallisches Element. Berichte der Deutschen Chemischen Gesellschaft 19: 210-211.

69. Rouxel, O, Luais, B (2017) Germanium isotope geochemistry. Rev Mineral Geochem 82: 601-656.

70. Froehlich, PN, Andreae, MO (1981) The marine geochemistry of germanium: ekasilocon. Science 213: $205-207$.

71. Armbrust, EV (2009) The life of diatoms in the world's oceans. Nature 459: 185-192.

72. Sutton, J, Ellwood, MJ, Maher, WA, Croot, PL (2010) Oceanic distribution of inorganic germanium relative to silicon: germanium discrimination by diatoms. Glob. Biogeochem. Cycles 24: GC2017, 10.019/2009GB003689.

73. Froelich, PN et al. (1992) River fluxes of dissolved silica to the ocean were higher during glacials: Ge/Si in diatoms, rivers and oceans. Paleoceanography 7: 739-767.

74. Hammond, DE, McManus, J, Berelson, WM (2004) Oceanic germanium/silicon ratios: evaluation of the potential overprint of temperature on weathering signals. Paleoceanography 19: PA2016, 10.1029/2003PA000940.

75. Pfänder, JA, Münker, C, Stracke, A, Mezger, K (2007) Nb/Ta and Zr/Hf in ocean island basalts - implications for crust-mantle differentiation and the fate of niunium. Earth Planet Sci Lett 254: 158-172.

76. Firdaus ML, Minami T, Norisuye, K Sohrin, Y (2011) Strong elemental fractionation of Zr-Hf and Nb-Ta across the Pacific Ocean. Nature Geosci 4: 227-230.

77. Lea, DW (2014) Elemental and isotopic proxies of past ocean temperatures. Treatise in Geochemistry 8: 373-397.

78. Billups, K and Schrag, DP (2003) Applications of benthic foraminiferal $\mathrm{Mg} / \mathrm{Ca}$ ratios to questions of Cenozoic climate change. Earth Planet. Sci. Lett. 209: 181-195.

79. Lea, DW, Pak, DK, Peterson, LC, Hughen, KA (2003) Synchroneity of tropical and high-latitude Atlantic temperatures over the last glacial termination. Science 301: 1361-1364.

80. Beck, JW et al. (1992) Sea-surface temperatures from coral skeletal strontium/calcium ratios. Science 257: 644-647.

81. Hendy, EJ, Gagan, MK, Alibert, CA, McCulloch, MT, Lough, JM, Isdale, PJ (2002) Abrupt decrease in tropical Pacific sea surface salinity at end of Little Ice Age. Science 295: 1511-1514.

82. Lea, DW, Boyle, AE (1991) Barium in planktonic foraminifera. Geochim Cosmochim Acta 55: 3321-3331.

83. Hemsing, F. et al. (2018) Barium isotopes in cold-water corals. Earth Planet Sci Lett 491: 183-192.

84. Faure, G (1986) Principles of isotope geology, $2^{\text {nd }}$ edn. Wiley, NY.

85. von Weizsäcker CF (1937) Über die Möglichkeit eines dualen-Zerfalls von Kalium. Physik Zeitschrift 38: 623-624.

86. Renne, PR, Mundil, R. Balco, G, Min, K, Ludwig, KR (2010) Joint determination of ${ }^{40} \mathrm{~K}$ decay constants and ${ }^{40} \mathrm{Ar}{ }^{*} /{ }^{40} \mathrm{~K}$ for the Fish Canyon sanidine standard, and improved accuracy for ${ }^{40} \mathrm{Ar} /{ }^{39} \mathrm{Ar}$ geochronology. Geochim Cosmochim Acta 74: 5349-5367.

87. Hart, SR (1964) The petrology and isotope mineral age relations of a contact zone in the Front Range, Colorado. J Geol 72, 493-525.

88. Harrison, TM, Duncan, I, McDougall, I (1985) Diffusion of ${ }^{40} \mathrm{Ar}$ in biotite: temperature, pressure and compositional effects. Geochim Cosmochim Acta 49: 2461-2468.

89. Rotenberg, E, Davis, DW, Amelin, Y, Ghosh, S, Bergquist, BA (2012) Determination of the decay-constant of ${ }^{87} \mathrm{Rb}$ 
by laboratory accumulation of ${ }^{87} \mathrm{Sr}$. Geochim Cosmochim Acta 85, 41-57.

1263

1264

1265

1266

1267

1268

1269

1270

1271

1272

1273

1274

1275

1276

1277

1278

1279

1280

1281

1282

1283

1284

1285

1286

1287

1288

1289

1290

1291

1292

1293

1294

1295

1296

1297

1298

1299

1300

1301

1302

1303

1304

1305

1306

1307

1308

1309
90. Cherniak, DJ, Watson, EB (1995) A study of diffusion in plagioclase using Rutherford backscattering spectroscopy. Geochim Cosmochim Acta 58: 5179-5190.

91. Rudnick, R, Gao, S (2003) Composition of the continental crust. Treatise on Geochemistry 3: 1-64.

92. Rollinson, HR (1993) Using geochemical data: evaluation, presentation, interpretation. Longman, Harlow, UK.

93. Sun, SS, McDonough, WF (1989) Chemical and isotopic systematics of oceanic basalts: implications for mantle composition and processes. Geol Soc Spec Publ 42: 313-345.

94. Alibo, DS, Nozaki, Y (1999) Rare earth elements in seawater: particle association, shale-normalization, and Ce oxidation. Geochim Cosmochim Acta 63: 363-372.

95. Bau, M, Dulski, P (1999) Comparing yttrium and rare earths in hydrothermal fluids from the Mid-Atlantic Ridge: implications for $\mathrm{Y}$ and REE behaviour during near-vent mixing and for the $\mathrm{Y} / \mathrm{Ho}$ ratio of Proterozoic seawater. Chem Geol 155: 77-90.

96. Blundy, JD, Robinson, JAC, Wood, BJ (1998) Heavy REE are compatible in clinopyroxene on the spinel lherzolite solidus. Earth Planet. Sci. Lett. 160: 493-504.

97. Taylor, SR, McLennan, SM (1981), The composition and evolution of the continental crust: Rare earth element evidence from sedimentary rocks, Philos. Trans. R. Soc. London, Ser. A, 301: 381-399.

98. Bhatia, MR, Crook, KA (1986) Trace element characteristics of greywackes and tectonic setting discrimination of sedimentary basins. Contrib Mineral Petrol 92: 181-193.

99. McLennan, SM, Hemming, S, McDaniel, DK, Hanson, GN (1993) Geochemical approaches to sedimentation, provenance, and tectonics. Geol Soc Am Spec Pap 21-21.

100. Ferrat, M. et al. (2011) Improved provenance tracing of Asian dust sources using rare earth elements and selected trace elements for palaeomonsoon studies on the eastern Tibetan Plateau. Geochim Cosmochim Acta 75: 6374-6399.

101. Ferrat, M, Weiss, DJ, Spiro, B, Large, D (2012) The inorganic geochemistry of a peat deposit on the eastern QinghaiTibetan Plateau and insights into changing atmospheric circulation in central Asia during the Holocene. Geochim Cosmochim Acta 91: 7-31.

102. Byrne, RH, Sholkovitz, ER (1996) Marine chemistry and geochemistry of the lanthanides. Handbook on the physics and chemistry of rare earths 23: 497-593.

103. Murray, RW, Buchholtz ten Brink, MR, Jones, DL, Gerlach, DC, Russ III, GP (1990) Rare earth elements as indicators of different marine depositional environments in chert and shale. Geology 18: 268-271.

104. Elderfield, H (1988) The oceanic chemistry of the rare-earth elements. Philos. Trans. Royal Soc. A 325: $105-126$.

105. Elderfield, H, Greaves, MJ (1982) The rare earth elements in seawater. Nature 296: 214.

106. Zheng, XY, Plancherel, Y, Saito, MA, Scott, PM, Henderson, GM (2016) Rare earth elements (REEs) in the tropical South Atlantic and quantitative deconvolution of their non-conservative behavior. Geochim. Cosmochim. Acta 177: $217-$ 237.

107. Richard, P, Shimizu, N, Allegre, CJ (1976) ${ }^{143} \mathrm{Nd} /{ }^{144} \mathrm{Nd}$, a natural tracer: an application to oceanic basalts. Earth Planet Sci Lett 31: 269-278.

108. Vance, D, Thirlwall, M (2002) ) An assessment of mass discrimination in MC-ICPMS using Nd isotopes. Chem Geol 185: 227-240.

109. Vance, D, O’Nions, RK (1990) Isotopic chronometry of zoned garnets: growth kinetics and metamorphic histories. Earth Planet Sci Lett 97: 227-240.

110. Vance, D, Strachan, RA, Jones, KA (1988) Extensional versus compressional settings for metamorphism: garnet chronometry and P-T-t histories in the Moine Supergroup, northwest Scotland. Geology 26: 927-930.

111. Vance, D, Harris, NBW (1998) The timing of prograde metamorphism in the Zanskar Himalaya, Geology 27: $395-$ 398.

112. Baxter, EF, Ague, JJ, De Paolo, DJ (2002) Prograde temperature-time evolution in the Barrovian type-locality constrained by Sm/Nd garnet ages from Glen Clova, Scotland. J. Geol Soc Lond 159: 71-82.

113. DePaolo, DJ, Wasserburg, GJ (1976) Inferences about magma sources and mantle structure from variations of $143 \mathrm{Nd} / 144 \mathrm{Nd}$. Geophys Res Lett 3: 743-746. 
1310 114. Jacobsen, SB, Wasserburg, GJ (1980) Sm-Nd isotope evolution of chondrites. Earth Planet Sci Lett 50: 139-155.

1311 115. O'Nions, RK, Evenson, NM, Hamilton, PJ (1979) Geochemical modelling of mantle differentiation and crustal 1312 growth. J Geophys Res 84: 6091-6101.

1313 116. DePaolo, DJ (1980) Crustal growth and mantle evolution: inferences from models of element transport and Nd and 1314 Sr isotopes. Geochim Cosmochim Acta 44: 1185-1196.

1315 117. Nelson, De Paolo (1985) Rapid production of continental crust 1.7 to 1.9 b.y. ago: Nd isotopic evidence from the 1316 basement of the North American mid-continent. Bull Geol Soc Amer 96: 746-754.

1317 118. Goldstein, SJ, Jacobsen, SB (1988) Nd and Sr isotopic systematics of river-water suspended material: implications 1318 for crustal evolution. Earth Planet Sci Lett 87: 249-265.

1319 119. Boyet, M, Carlson, RL (2005) ${ }^{142} \mathrm{Nd}$ evidence for early ( $\left.>4.3 \mathrm{Ga}\right)$ global differentiation of the silicate Earth. Science 1320 309: 576-581.

1321 120. Caro, G, Bourdon, B, Halliday, AN, Quitte, G (2008) Super-chondritic Sm/Nd ratio in Mars, Earth, and the Moon. 1322 Nature 452: 336-339.

1323 121. Hofmann, AW, White, WM. (1982) Mantle plumes from ancient oceanic crust. Earth Planet Sci Lett 57: 421-436.

1324 122. Hawkesworth, CJ, Kemp, AIS (2010) Using hafnium and oxygen isotopes in zircons to unravel the record of crustal 1325 evolution. Chem Geol 226: 144-162.

1326 123. Condie, KC, Aster, RC (2010) Episodic zircon age spectra of orogenic granitoids: the supercontinent connection and 1327 continental growth. Precam Res 180: 227-236.

1328

1329

1330

1331

1332

1333

1334

1335

1336

1337

1338

1339

1340

1341

1342

1343

1344

1345

1346

1347

1348

1349

1350

1351

1352

1353

1354

1355

1356
124. Kemp, AIS et al. (2010) Hadean crustal evolution revisited: new constraints from Pb-Hf isotope systematics of Jack Hills zircons. Earth Planet Sci Lett 296, 45-56.

125. Frank, M (2002) Radiogenic isotopes: tracers of past ocean circulation and erosional input. Rev. Geophys. 40: 1-38.

126. Goldstein, S. L., Hemming, S. R. (2003). Long-lived isotopic tracers in oceanography, paleoceanography, and icesheet dynamics. Treatise on geochemistry 6: 453-489.

127. Jeandel, C, Arsouze, T, Lacan, F, Techine, P, Dutay, JC. (2007) Isotopic Nd compositions and concentrations of the lithogenic inputs into the ocean: A compilation, with an emphasis on the margins. Chem Geol 239: 156-164.

128. Piepgras, DJ, Wasserburg, GJ, Dasch, EJ (1979) The isotopic composition of Nd in different ocean masses. Earth Planet Sci Lett 45: 223-236.

129. Piepgras, DJ, Wasserburg, GJ (1980) Neodymium isotopic variations in seawater. Earth Planet Sci Lett 50: 128138.

130. Piotrowski, AM, Goldstein, SL, Hemming, SR, Fairbanks, RG (2005) Temporal relationships of carbon cycling and ocean circulation at glacial boundaries. Science 307: 1933-1938.

131. van de Flierdt et al. (2016) Neodymium in the oceans: a global database, a regional comparison and implications for palaeoceanographic research. Phil Trans Roy Soc A 374: dx.doi.org/10.1098/rsta.2015.0293.

132. Lacan, F, Jeandel, C (2001) Tracing Papua New Guinea imprint on the central Equatorial Pacific Ocean using neodymium isotopic compositions and rare earth element patterns. Earth Planet Sci Lett 186: 497-512.

133. Abbott, AN, Haley, BA, McManus, J, Reimers, CE (2015) The sedimentary flux of dissolved rare earth elements to the ocean. Geochim Cosmochim Acta 154: 186-200.

134. Jeandel, C, Oelkers, EH (2015) The influence of terrigenous particulate material dissolution on ocean chemistry and global element cycles. Chem Geol 395: 50-66.

135. Cook, CP et al. (2013) Dynamic behaviour of the East Antarctic ice sheet during Pliocene warmth. Nature Geoscience 6: 765-769.

136. Wilson, DJ et al. (2018) Ice loss from the East Antarctic Ice Sheet during late Pleistocene interglacials. Nature 561: 383-386.

137. Bigeleisen, J, Mayer, MG (1947) Calculation of equilibrium constants for isotopic exchange reactions. J Chem Phys 15: 261-267.

138. Spivack, AJ, Edmond, JM (1987) Boron isotope exchange between seawater and the oceanic crust. Geochim Cosmochim Acta 51: 1033-1043. 
1357

139. Chan, LH, Edmond, JM (1988) Variation of lithium isotope composition in the marine environment: A preliminary report. Geochim Cosmochim Acta 52: 1711-1717.

140. Valley JW, Cole D (eds) (2001) Stable Isotope Chemistry. Rev Geochem Mineral 43, Mineralogical Society of America, Washington DC.

141. Penniston-Dorland, S, Liu, XM, Rudnick, RL (2017) Lithium isotope geochemistry. Rev Mineral Geochem 82: 165 217.

142. Marschall, H, Foster, G (eds) (2018) Boron Isotopes: The Fifth Element. Advances in Isotope Geochemistry. Springer, Cham.

143. Beard, BL, Johnson, CM, Cox, L, Sun, H, Nealson, KH, Aguilar, C (1999) Iron isotope biosignatures. Science 285 : 1889-1892.

144. Cameron, V, Vance, D, Archer, C, House, CH (2009) A biomarker based on the stable isotopes of nickel. Proc Natl Acad Sci 106: 10944-10948.

145. Martin, JH, Fitzwater, SE (1988) Iron deficiency limits phytoplankton growth in the north-east Pacific subarctic. Nature 331: 341-343.

146. Walder, AJ, Freedman, PA (1992) Isotopic ratio measurement using a double focusing magnetic sector mass analyser with an inductively coupled plasma as an ion source. J Anal Atom Spectrom 7: 571-575.

147. Johnson, CM, Beard, BL, Albarede, F (eds) (2004) Geochemistry of Non-Traditional Stable Isotopes. Rev Mineral Geochem 55. The Mineralogical Society of America, Washington DC.

148. Woodland, SJ, Rehkämper, M, Halliday, AN, Lee, DC, Hattendorf, B, Günther, D (2005) Accurate measurement of silver isotopic compositions in geological materials including low Pd/Ag meteorites. Geochim. Cosmochim. Acta 69: 2153-2163.

149. Creech, J, Baker, J, Handler, M, Schiller, M, Bizzarro, M (2013) Platinum stable isotope ratio measurements by double-spike multiple collector ICPMS. J Anal Atom Spectrom 28: 853-865.

150. Creech, JB, Moynier, F, Bizzarro, M (2017) Tracing metal-silicate segregation and late veneer in the Earth and the ureilite parent body with palladium stable isotopes. Geochim Cosmochim Acta 216: 28-41.

151. Breton, T, Quitté, G (2014) High-precision measurements of tungsten stable isotopes and application to earth sciences. J Anal Atom Spectrom 29: 2284-2293.

152. Abraham, K, Barling, J, Siebert, C, Belshaw, N, Gall, L, Halliday, AN (2015) Determination of mass-dependent variations in tungsten stable isotope compositions of geological reference materials by double-spike and MC-ICPMS. J Anal Atom Spectrom 30: 2334-2342.

153. Teng, F-Z, Watkins, JM, Dauphas, N (eds) (2017) Non-Traditional Stable Isotopes. Rev Mineral Geochem 82. The Mineralogical Society of America, Washington DC.

154. Nanne, JA, Millet, MA, Burton, KW, Dale, CW, Nowell, GM, Williams, HM (2017) High precision osmium stable isotope measurements by double spike MC-ICP-MS and N-TIMS. J Anal Atom Spectrom 32: 749-765.

155. Kendall, B, Dahl, TW, Anbar, AD (2017) The stable isotope geochemistry of molybdenum. Rev Mineral Geochem 82: 683-732.

156. Collier, RW (1985) Molybdenum in the Northeast Pacific Ocean 1. Limnol Oceanogr 30: 1351-1354.

157. Barling, J, Arnold, GL, Anbar, AD (2001) Natural mass-dependent variations in the isotopic composition of molybdenum. Earth Planet Sci Lett 193: 447-457.

158. Barling, J, Anbar, AD (2004) Molybdenum isotope fractionation during adsorption by manganese oxides. Earth Planet Sci Lett 217: 315-329.

159. Helz, GR et al.(1996) Mechanism of molybdenum removal from the sea and its concentration in black shales: EXAFS evidence. Geochim Cosmochim Acta 60: 3631-3642.

160. Erickson, BE, Helz, GR (2000) Molybdenum (VI) speciation in sulfidic waters: stability and lability of thiomolybdates. Geochim Cosmochim Acta 64: 1149-1158.

161. Neubert, N, Nägler, TF, Böttcher, ME (2008) Sulfidity controls molybdenum isotope fractionation into euxinic sediments: Evidence from the modern Black Sea. Geology 36: 775-778. 
1404 1405

1406 1407

1408

1409

1410

1411

1412

1413

1414

1415

1416

1417

1418

1419

1420

1421

1422

1423

1424

1425

1426

1427

1428

1429

1430

1431

1432

1433

1434

1435

1436

1437

1438

1439

1440

1441

1442

1443

1444

1445

1446

1447

1448

1449

1450

162. Arnold, GL, Anbar, AD, Barling, J, Lyons, TW (2004) Molybdenum isotope evidence for widespread anoxia in midProterozoic oceans. Science 304): 87-90.

163. Dahl, TW et al. (2010) Devonian rise in atmospheric oxygen correlated to the radiations of terrestrial plants and large predatory fish. Proc Natl Acad Sci 107: 17911-17915.

164. Reinhard, CT et al. (2013) Proterozoic ocean redox and biogeochemical stasis. Proc Natl Acad Sci 110: 5357-5362. 165. Ciscato, ER, Bontognali, TR, Vance, D (2018) Nickel and its isotopes in organic-rich sediments: implications for oceanic budgets and a potential record of ancient seawater. Earth Planet Sci Lett 494: 239-250.

166. Little, SH, Vance, D, Walker-Brown, C, Landing, WM (2014) The oceanic mass balance of copper and zinc isotopes, investigated by analysis of their inputs, and outputs to ferromanganese oxide sediments. Geochim Cosmochim Acta 125: 673-693.

167. Maréchal, CN, Nicolas, E, Douchet, C, Albarède, F (2000) Abundance of zinc isotopes as a marine biogeochemical tracer. Geochem Geophys Geosys 1: 10.1029/1999GC000029.

168. Francois, R et al. (1997) Contribution of Southern Ocean surface-water stratification to low atmospheric $\mathrm{CO}_{2}$ concentrations during the last glacial period. Nature 389: 929-935.

169. John, SG, Geis, RW, Saito, MA, Boyle, EA (2007) Zinc isotope fractionation during high-affinity and low-affinity zinc transport by the marine diatom Thalassiosira oceanica. Limnol Oceanogr 52: 2710-2714.

170. Köbberich, M, Vance, D (2019) Zn isotope fractionation during uptake into marine phytoplankton: Implications for oceanic zinc isotopes. Chem Geol, in press.

171. Schlitzer, R, Anderson, RF, Masferrer Dodas, E, et al. (2018) The GEOTRACES intermediate data product 2017. Chem Geol 493: 210-223.

172. Schlitzer, R (2019) eGEOTRACES - Electronic Atlas of GEOTRACES Sections and Animated 3D Scenes. http://www.egeotraces.org

173. Cameron, V, Vance, D (2014) Heavy nickel isotope compositions in rivers and the oceans. Geochim Cosmochim Acta 128: 195-211.

174. Takano, S et al. (2017) A simple and rapid method for isotopic analysis of nickel, copper, and zinc in seawater using chelating extraction and anion exchange. Anal Chim Acta 967: 1-11.

175. Wang, RM, Archer, C, Bowie, AR, Vance, D (2019) Zinc and nickel isotopes in seawater from the Indian Sector of the Southern Ocean: The impact of natural iron fertilization versus Southern Ocean hydrography and biogeochemistry. Chem Geol 511: 452-464.

176. Irving, H, Williams, RJP (1948) Order of stability of metal complexes. Nature 162: 746-747.

177. Vance, D et al. (2008) The copper isotope geochemistry of rivers and the oceans. Earth Planet Sci Lett 274: 204213.

178. Little, SH, Vance, D, McManus, J, Severmann, S, Lyons, TW (2017) Copper isotope signatures in modern marine sediments. Geochim Cosmochim Acta 212: 253-273.

179. Zhao, Y, Vance, D, Abouchami, W, de Baar, HJ (2014) Biogeochemical cycling of zinc and its isotopes in the Southern Ocean. Geochim Cosmochim Acta 125: 653-672.

180. Conway, TM, John, SG (2014) The biogeochemical cycling of zinc and zinc isotopes in the North Atlantic Ocean. Global Biogeochem Cycles 28: 1111-1128.

181. Bryan, AL, Dong, S, Wilkes, EB, Wasylenki, LE (2015) Zinc isotope fractionation during adsorption onto Mn oxyhydroxide at low and high ionic strength. Geochim Cosmochim Acta 157: 182-197.

182. Little, SH, Vance, D, McManus, J, Severmann, S (2016) Key role of continental margin sediments in the oceanic mass balance of $\mathrm{Zn}$ and $\mathrm{Zn}$ isotopes. Geology 44: 207-210.

\section{Acknowledgements}

We are grateful to Tina van de Flierdt and editor Michael Mingos for their comments on an earlier version of this chapter. 


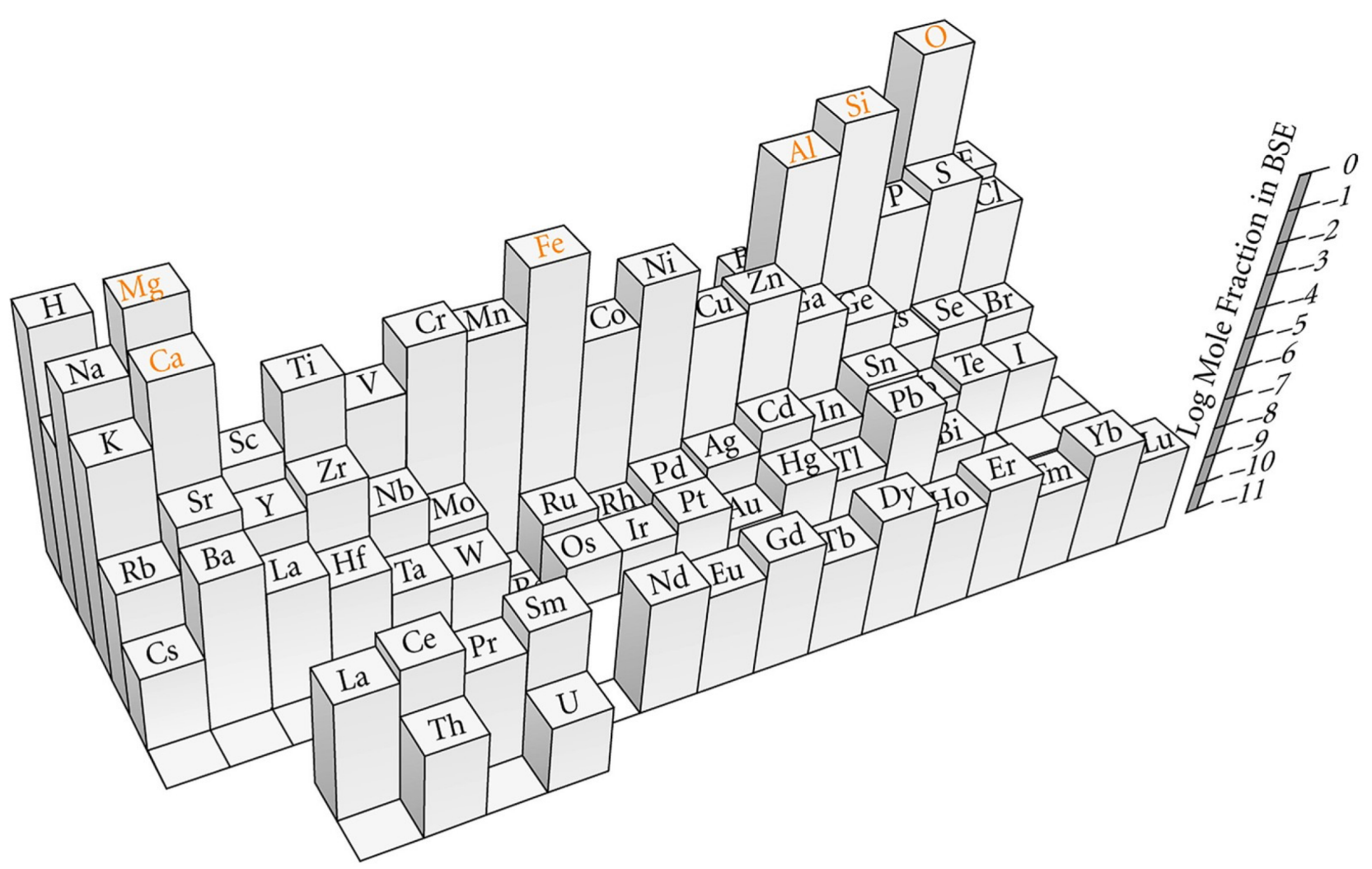

Figure 1: A periodic table of the elements, illustrating the abundances of the elements in the bulk silicate Earth 1459 (today's mantle and crust) as a 3-dimensional histogram (note the log scale). The six "major elements", making 1460 up $99.1 \%$ of the silicate portion of the Earth, are labelled in orange. Taken from White (2013). Reproduced with permission. 


\section{2}

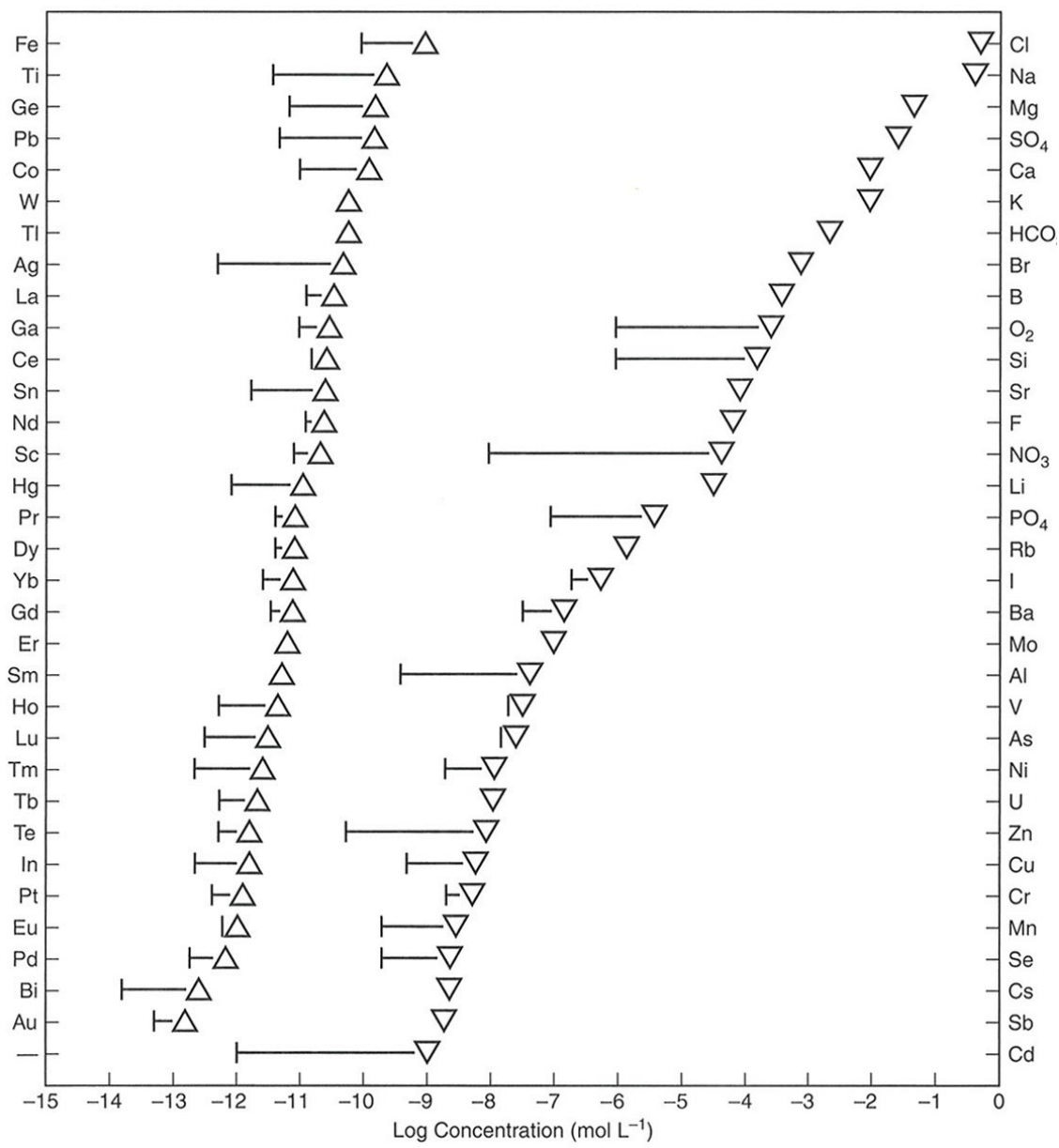

1463

1464

1465

1466

1467

1468

1469
Figure 2: Variability in dissolved concentrations in seawater - note the log scale. The inverted triangles show the average dissolved concentration of each element, in the global ocean the associated uncertainty its variability. Reproduced from [18] with permission of Princeton University Press 


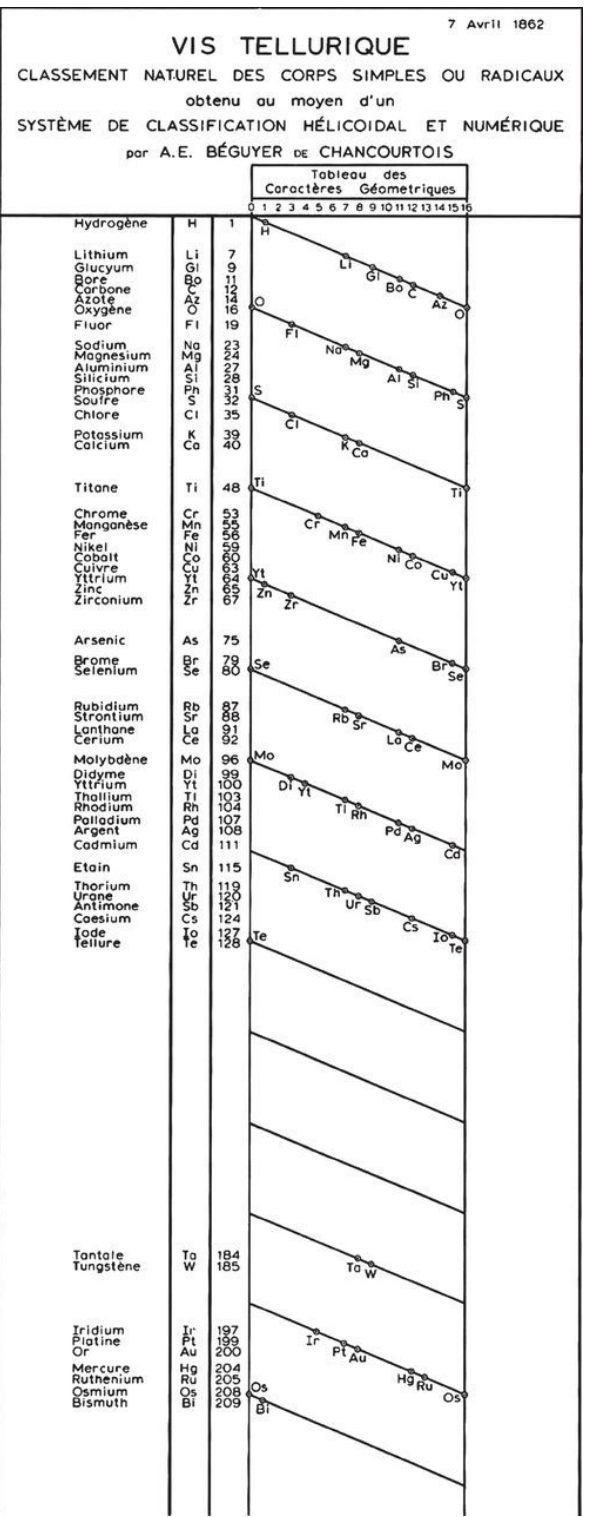

Figure 3: The telluric screw of Alexandre Emile Béguyer de Chancourtois [54]. This early classification system, from a geologist, is a three-dimensional concept, with the elements arranged along a spiral. Each turn of the screw or spiral returns one to an element with similar properties. 


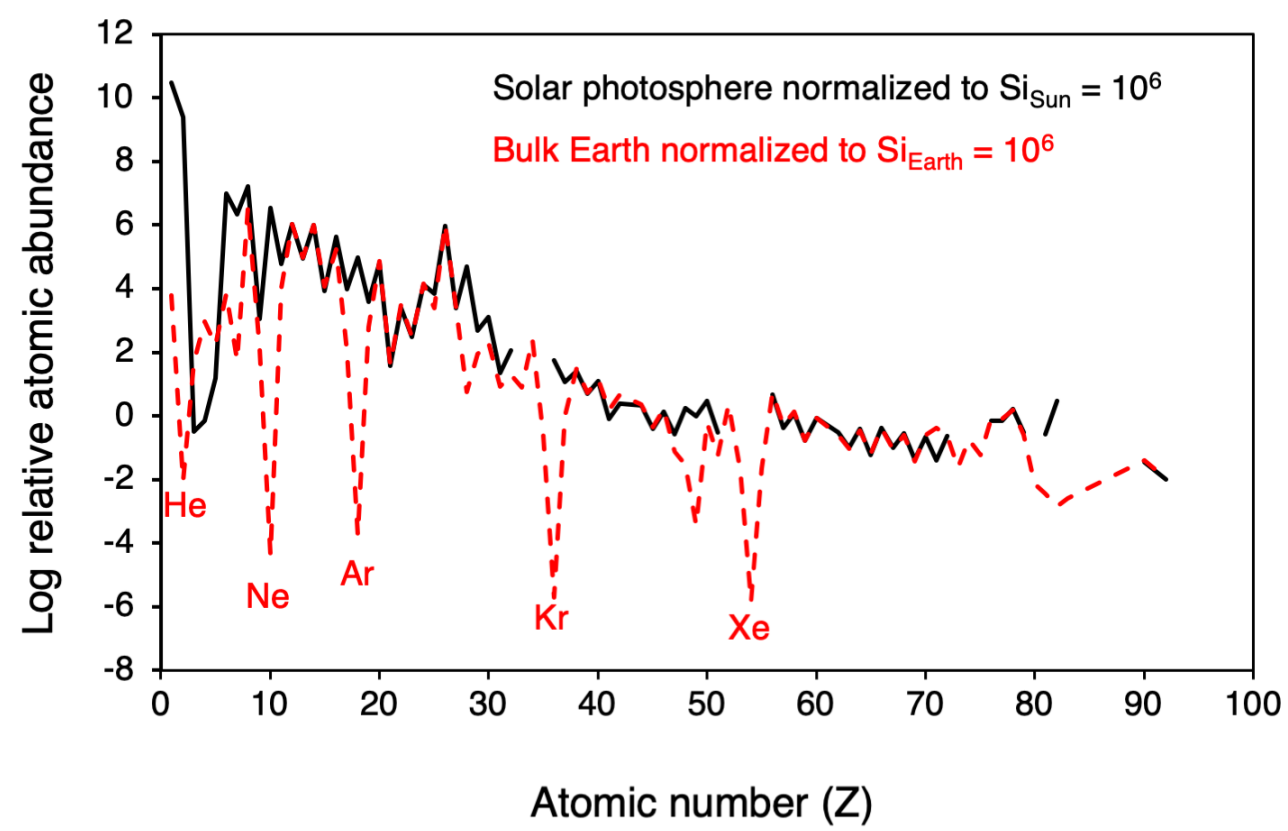

1481

1482

1483

1484

1485

1486

1487

1488

1489

1490

1491

1492

Figure 4: Estimates of the relative atomic abundances of the elements for the bulk Solar System (from the solar photosphere normalised to $\mathrm{Si}_{\text {Sun }}=10^{6} ;[58]$ ) and for the bulk Earth (normalised to $\mathrm{Si}_{\text {Earth }}=10^{6}$; [59]). The original data for the noble gases on Earth were given in units of $10^{-8} \mathrm{ccSTP} / \mathrm{g}$ and are here converted to atomic abundances using a molar volume of $22,400 \mathrm{ccSTP} / \mathrm{mole}$ and standard temperatures and pressures. Notable features of the Solar abundance pattern are the overall decrease in abundance with increasing atomic number and the zig-zag pattern for even versus odd atomic numbers, due to the greater stability of nuclei with even numbers of protons in nucleosynthetic environments. The Earth, by comparison, show a strong depletion in the volatile elements relative to both the Sun, especially for the noble gases. 


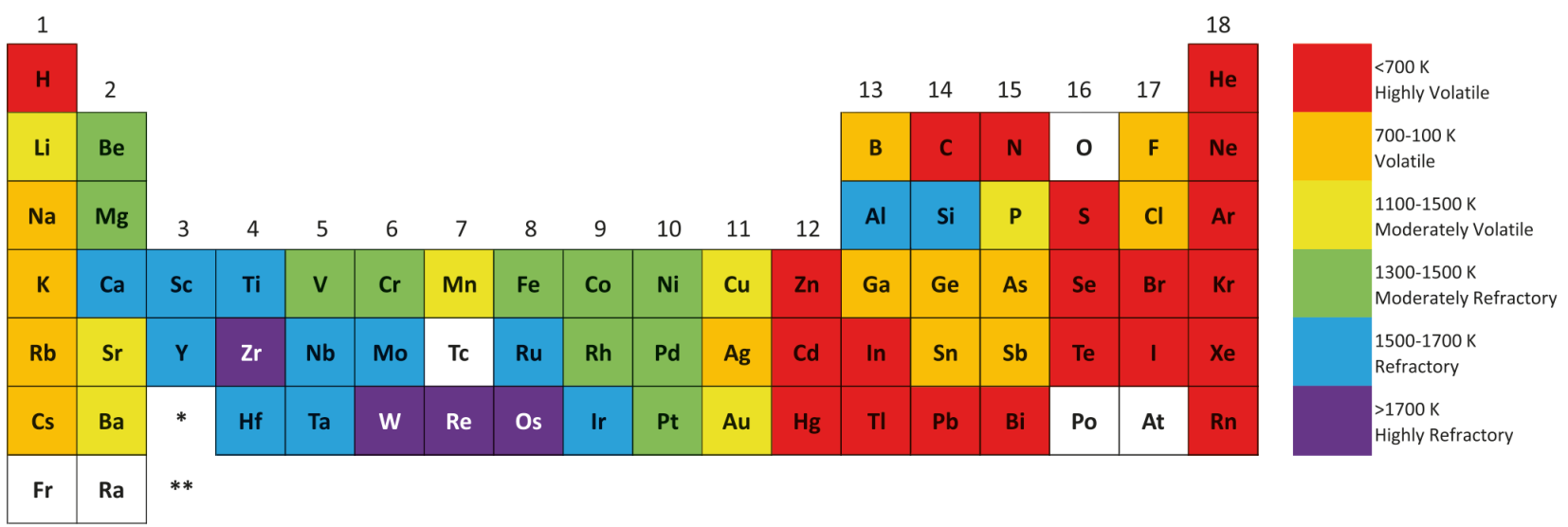

\begin{tabular}{|l|l|l|l|l|l|l|l|l|l|l|l|l|l|l|l|}
\hline$*$ & La & Ce & Pr & Nd & $\mathrm{Pm}$ & $\mathrm{Sm}$ & $\mathrm{Eu}$ & $\mathrm{Gd}$ & $\mathrm{Tb}$ & $\mathrm{Dy}$ & $\mathrm{Ho}$ & $\mathrm{Er}$ & $\mathrm{Tm}$ & $\mathrm{Yb}$ & $\mathrm{Lu}$ \\
\hline \multirow{2}{**}{} & $\mathrm{Ac}$ & $\mathrm{Th}$ & $\mathrm{Pa}$ & $\mathrm{U}$ & $\mathrm{Np}$ & $\mathrm{Pu}$ & $\mathrm{Am}$ & $\mathrm{Cm}$ & $\mathrm{Bk}$ & $\mathrm{Cf}$ & $\mathrm{Es}$ & $\mathrm{Fm}$ & $\mathrm{Md}$ & No & $\mathrm{Lr}$ \\
\hline
\end{tabular}

Figure 5: A cosmochemical classification of the elements superimposed on the PTE [60], colour-coded to show the $50 \%$ condensation temperature (the temperature by which $50 \%$ of the element will condense from gaseous to solid or liquid state) calculated for a nebula with a solar composition and a pressure of $10^{-4}$ bar. Reproduced with permission. 
Figure 6: Goldschmidt's table showing the classification of the elements according to their geochemical affinity, into siderophile, chalcophile, lithophile, atmophile, and biophile elements [61]. Reproduced with 1511 permission.

Sulphide,
chalcophile.
((O)), S, Se, Te
Fe, Cr, (Ni), (Co)
$\mathrm{Cu}, \mathrm{Zn}, \mathrm{Cd}, \mathrm{Pb}$
$\mathrm{Sn}, \mathrm{Ge}, \mathrm{Mo}$
$\mathrm{As}, \mathrm{Sb}, \mathrm{Bi}$
$\mathrm{Ag},(\mathrm{Au}), \mathrm{Hg}$
$\mathrm{Pd}, \mathrm{Ru},(\mathrm{Pt})$
$\mathrm{Ga}, \mathrm{In}, \mathrm{Tl}$
(Cr)

lithophile.

$\mathrm{O},(\mathrm{S}),(\mathrm{P}),(\mathrm{H})$

$\mathrm{Si}, \mathrm{Ti}, \mathrm{Zr}, \mathrm{Hf}$, Th

$(\mathrm{Sn})$

$\mathrm{F}, \mathrm{Cl}, \mathrm{Br}, \mathrm{I}$

$\mathrm{B}, \mathrm{Al},(\mathrm{Ga}), \mathrm{Sc}, \mathrm{Y}$

La, Ce, Pr, Nd, Sm

$\mathrm{Eu}, \mathrm{Gd}, \mathrm{Tb}, \mathrm{Dy}$

$\mathrm{Ho}, \mathrm{Er}, \mathrm{Tu}, \mathrm{Yb}, \mathrm{Cp}$

$\mathrm{Li}, \mathrm{Na}, \mathrm{K}, \mathrm{Rb}, \mathrm{Cs}$

$\mathrm{Be}, \mathrm{Mg}, \mathrm{Ca}, \mathrm{Sr}, \mathrm{Ba}$

(Fe), V, Cr, Mn

((Ni)), ((Co)), Nb, Ta

W, U, ((C))

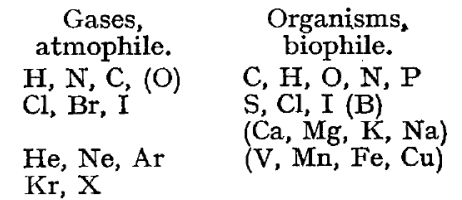

atmophile.

( Cl, I (B)

(V, Mn, Fe, Cu)

$\mathrm{Kr}, \mathrm{X}$

geochemical 


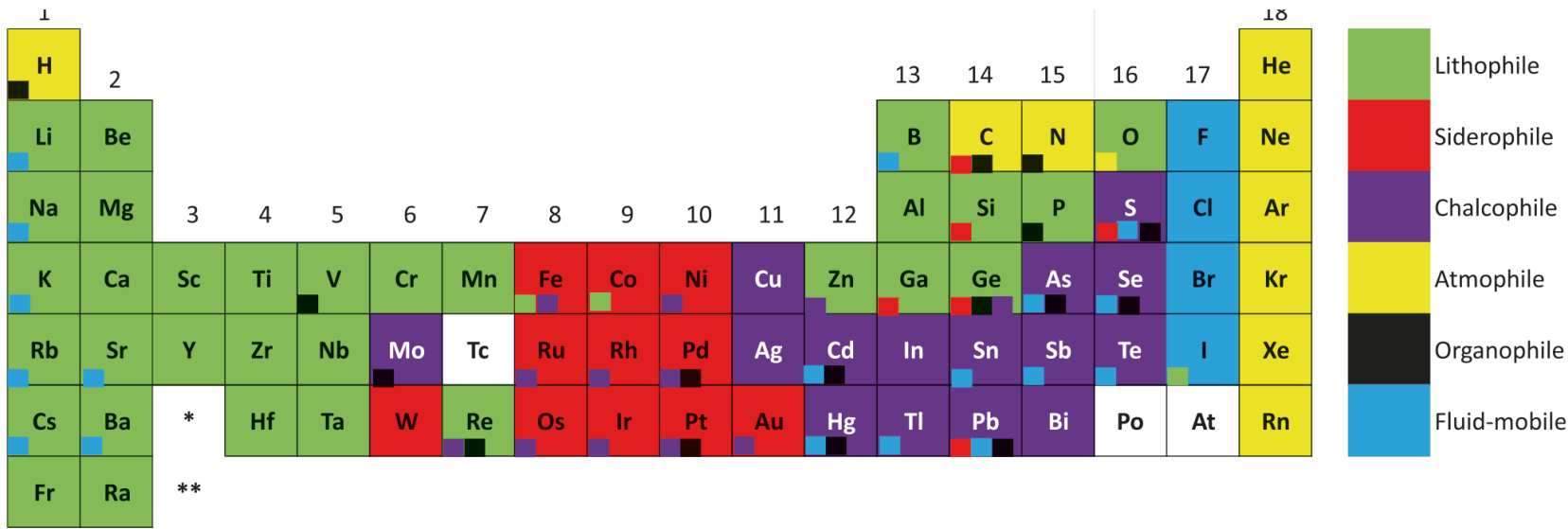

\begin{tabular}{|l|l|l|l|l|l|l|l|l|l|l|l|l|l|l|l|}
\hline$*$ & La & $\mathrm{Ce}$ & $\mathrm{Pr}$ & $\mathrm{Nd}$ & $\mathrm{Pm}$ & $\mathrm{Sm}$ & $\mathrm{Eu}$ & $\mathrm{Gd}$ & $\mathrm{Tb}$ & $\mathrm{Dy}$ & Ho & $\mathrm{Er}$ & $\mathrm{Tm}$ & $\mathrm{Yb}$ & Lu \\
\hline * & $\mathrm{Ac}$ & $\mathrm{Th}$ & $\mathrm{Pa}$ & $\mathrm{U}$ & $\mathrm{Np}$ & $\mathrm{Pu}$ & $\mathrm{Am}$ & $\mathrm{Cm}$ & $\mathrm{Bk}$ & $\mathrm{Cf}$ & $\mathrm{Es}$ & $\mathrm{Fm}$ & $\mathrm{Md}$ & No & Lr \\
\hline
\end{tabular}

Figure 7: One example of many published versions of the periodic table of the elements colour-coded for different categories in Goldschmidt's classification [60], broadly following Goldschmidt's original scheme but with the addition of a further category of fluid-mobile elements. The main colour given to each element reflects their dominant behaviour. The small squares reflect other possible behaviours. Reproduced with permission. 


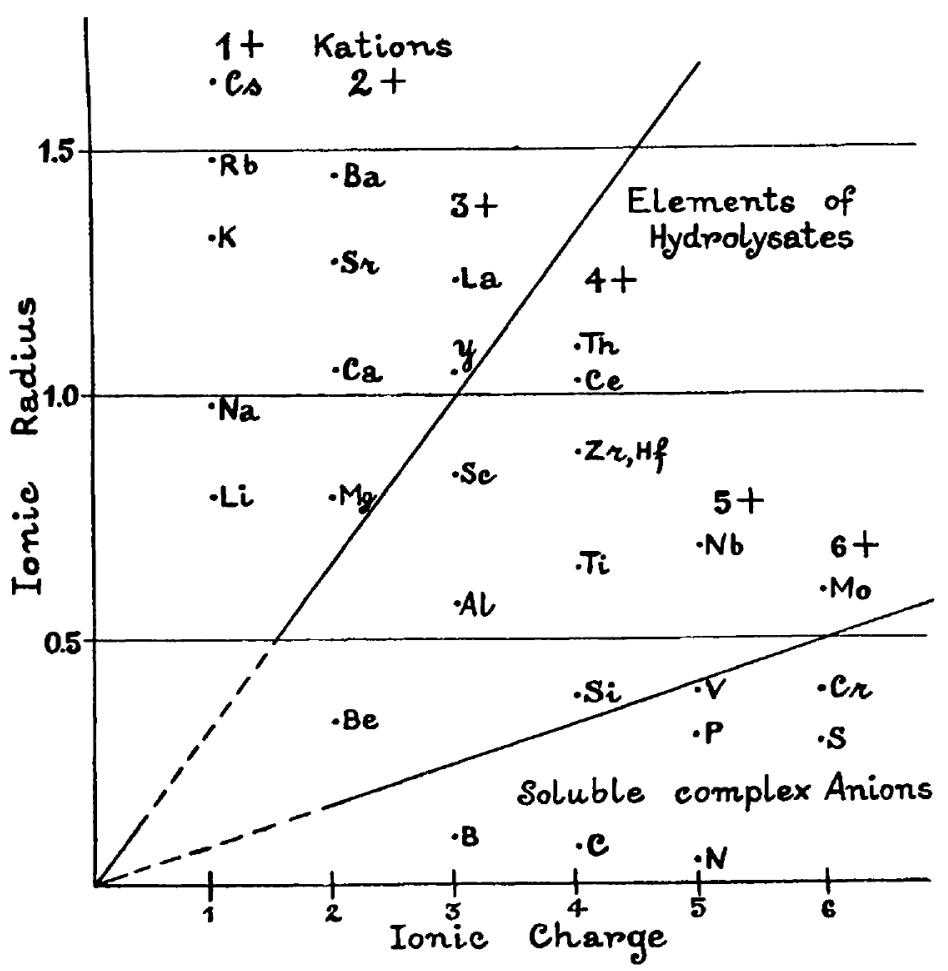

Figure 8: Goldschmidt extended his discussion of ionic radius and charge, as the organising parameters for the substitution of elements into igneous minerals, to aqueous solutions as well. The above figure (taken from [61]) shows his attempt to systematise the speciation behaviour of ions dissolved in aqueous fluids in terms of ionic potential. Reproduced with permission. 


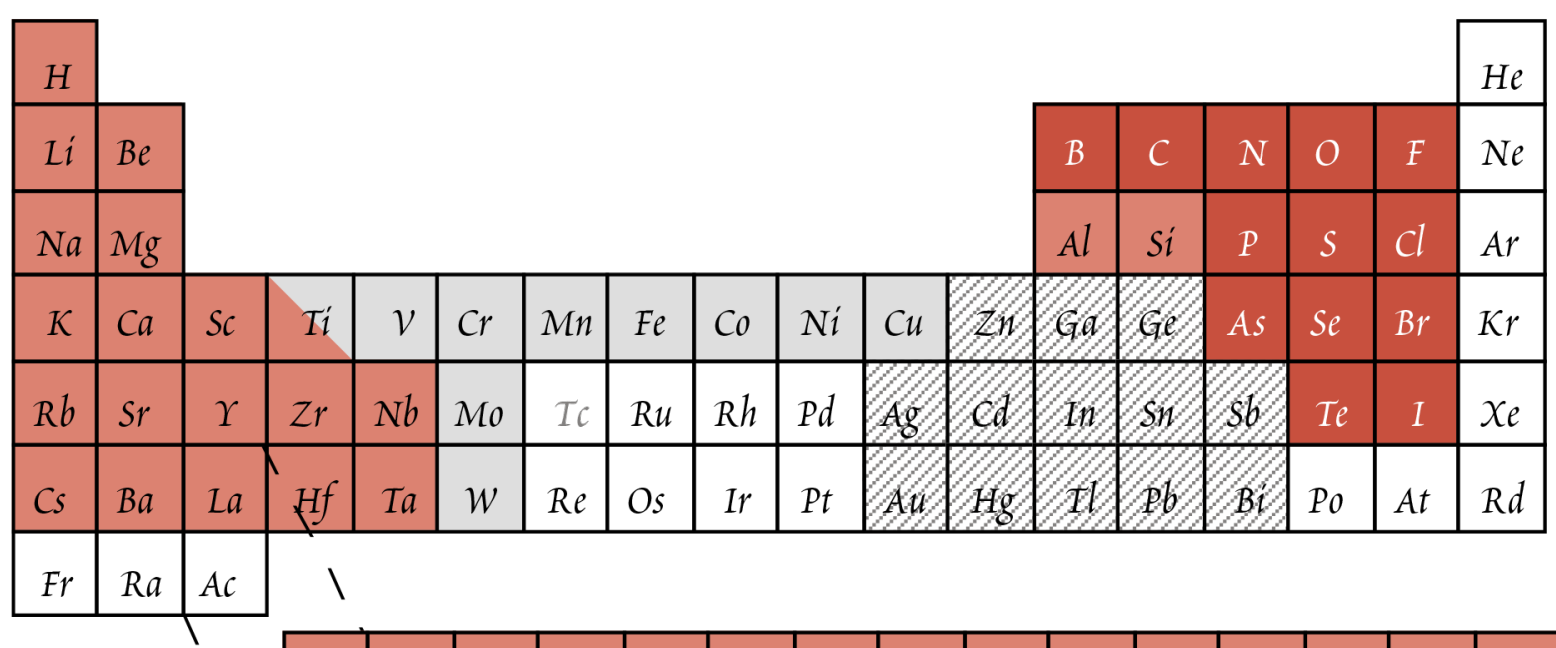

\begin{tabular}{|l|l|l|l|l|l|l|l|l|l|l|l|l|l|l|}
\hline$L a$ & $C e$ & $P r$ & $N d$ & $P m$ & $S m$ & $E u$ & $G d$ & $\tau b$ & $D y$ & $H o$ & $E r$ & $T m$ & $\Upsilon b$ & $L u$ \\
\hline$A c$ & $T h$ & $P a$ & $U$ & $N p$ & $P u$ & & & & & & & & & \\
\hline
\end{tabular}

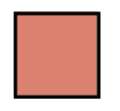
A-Metals Metals

Figure 9: A PTE-based classification of element behaviour in terms of complex formation in complex aqueous 


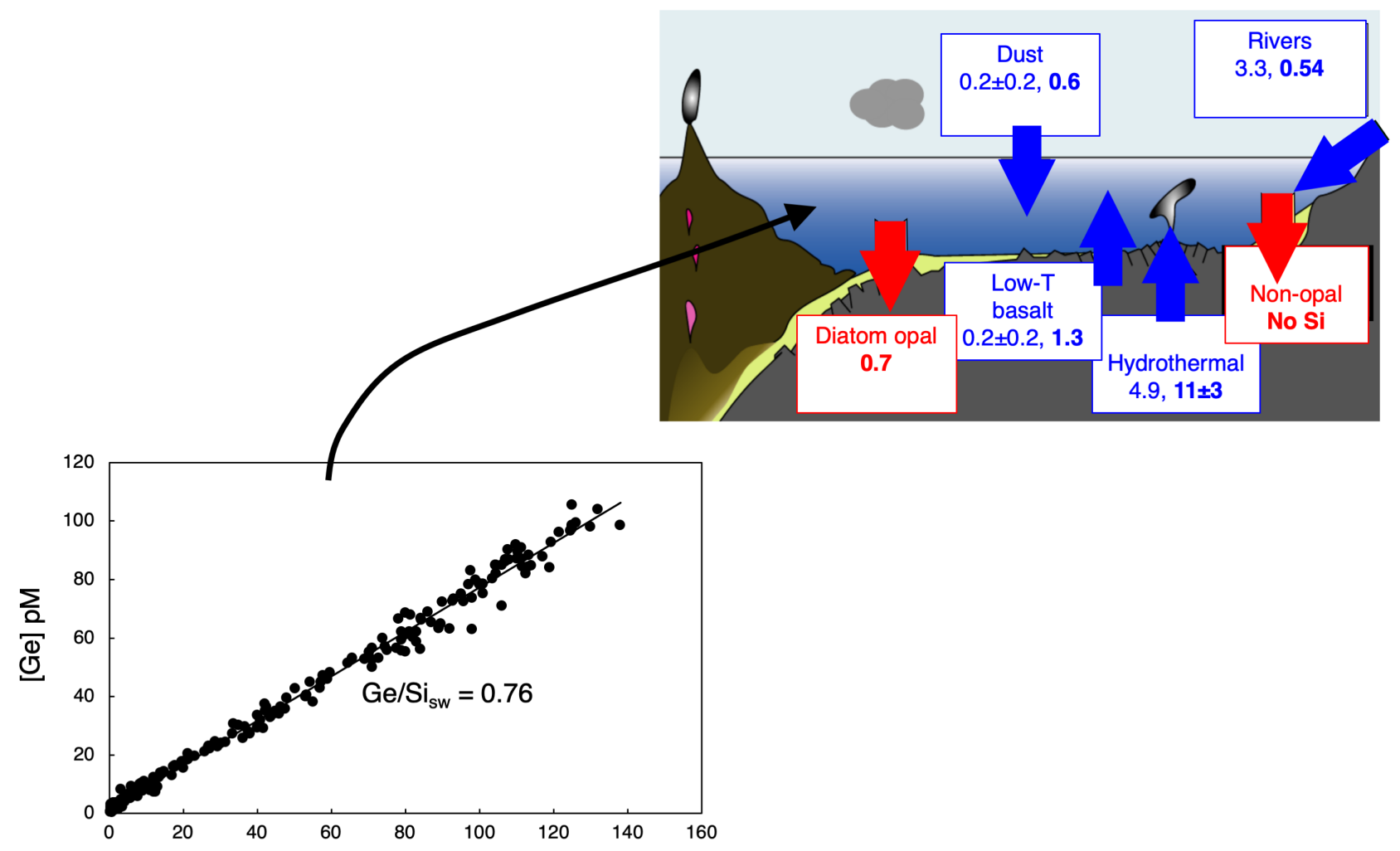

[Si] $\mu \mathrm{M}$

Figure 10: Germanium and silicon abundance data for seawater (bottom left), in this case from the South Pacific [72], showing the very tight coupling between Si and Mendeleev's ekasilicon in the dissolved pool of the oceans. The cartoon at top right is redrawn after Rouxel and Luais [69] and shows the best current estimate for the size (plain text, units of $10^{6} \mathrm{~mol} \mathrm{yr}^{-1}$ ) and $\mathrm{Ge} / \mathrm{Si}$ ratio (bold text, in $\mu \mathrm{mol} / \mathrm{mol}$ ) of the main input fluxes (blue) and the two known output fluxes with their Ge/Si ratio (red). 


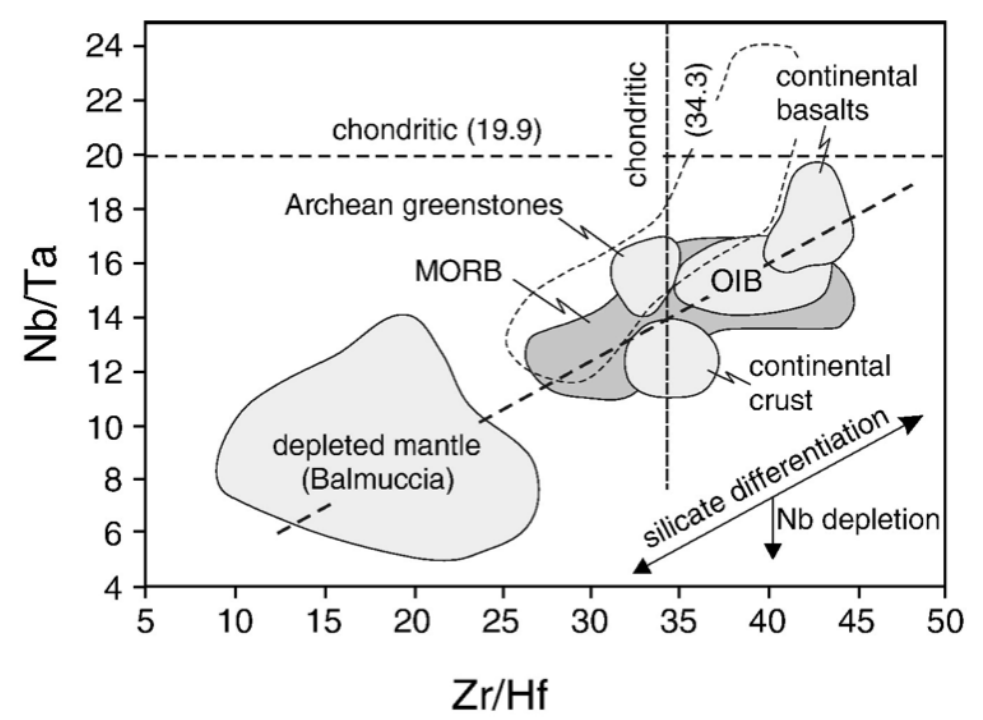

Figure 11: $\mathrm{Nb} / \mathrm{Ta}$ and $\mathrm{Zr} / \mathrm{Hf}$ ratios (by weight) in the major terrestrial silicate reservoirs (from [75]). As discussed in section 3.1, all thus far measured silicate reservoirs of the Earth are deficient in $\mathrm{Nb}$ relative to chondritic meteorites, suggesting either partitioning of $\mathrm{Nb}$ in to the core [46] or an unsampled reservoir in the deep mantle representing the remnants of subducted oceanic crust (e.g. [45]). OIB = oceanic island basalt), $\mathrm{MORB}=$ mid-ocean ridge basalt. Reproduced with permission. 
Vance and Little - Figure 12

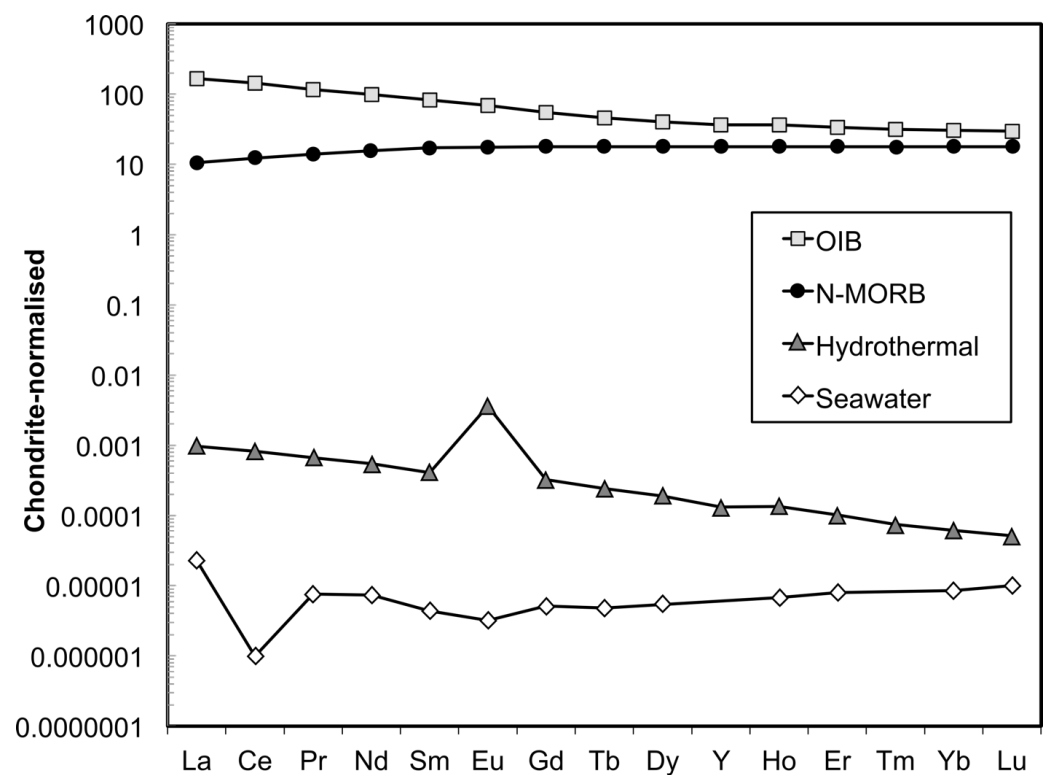

Figure 12. Chondrite-normalised REE patterns. Data for $\mathrm{C} 1$ chondrite, ocean island basalt (OIB) and normal mid-ocean ridge basalt (N-MORB) are from [92]. Data for Pacific seawater (2500m) are from [94] and for high temperature hydrothermal fluids are from [95]. 


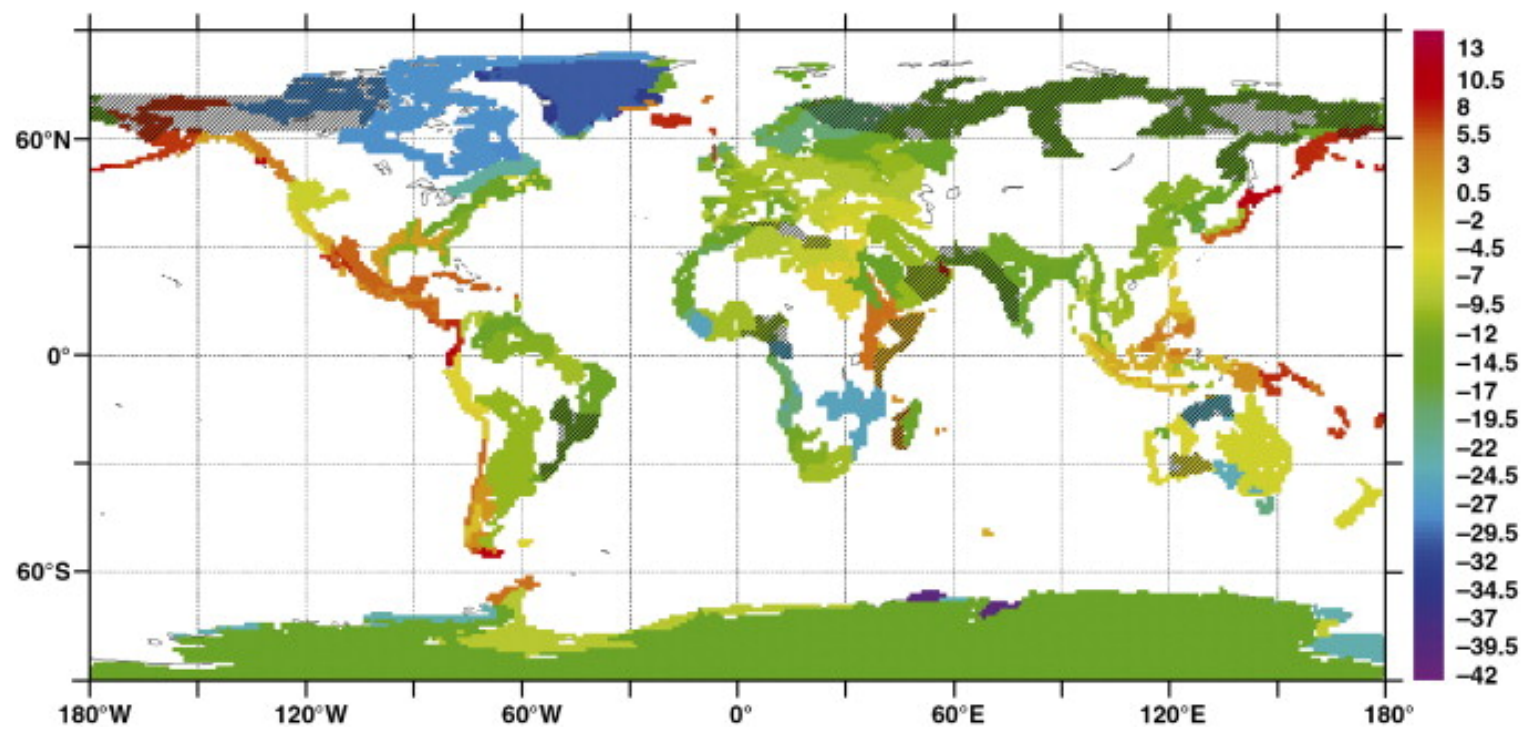

Figure 13. Map of the $\mathrm{Nd}$ isotope signature of continental margins extrapolated from discrete data (from [127]). Margin sediments are generally older and thus unradiogenic ( $\varepsilon_{\mathrm{Nd}}$ values - see text for explanation) surrounding the Atlantic and younger, and more radiogenic, surrounding the Pacific. Reproduced with permission. 


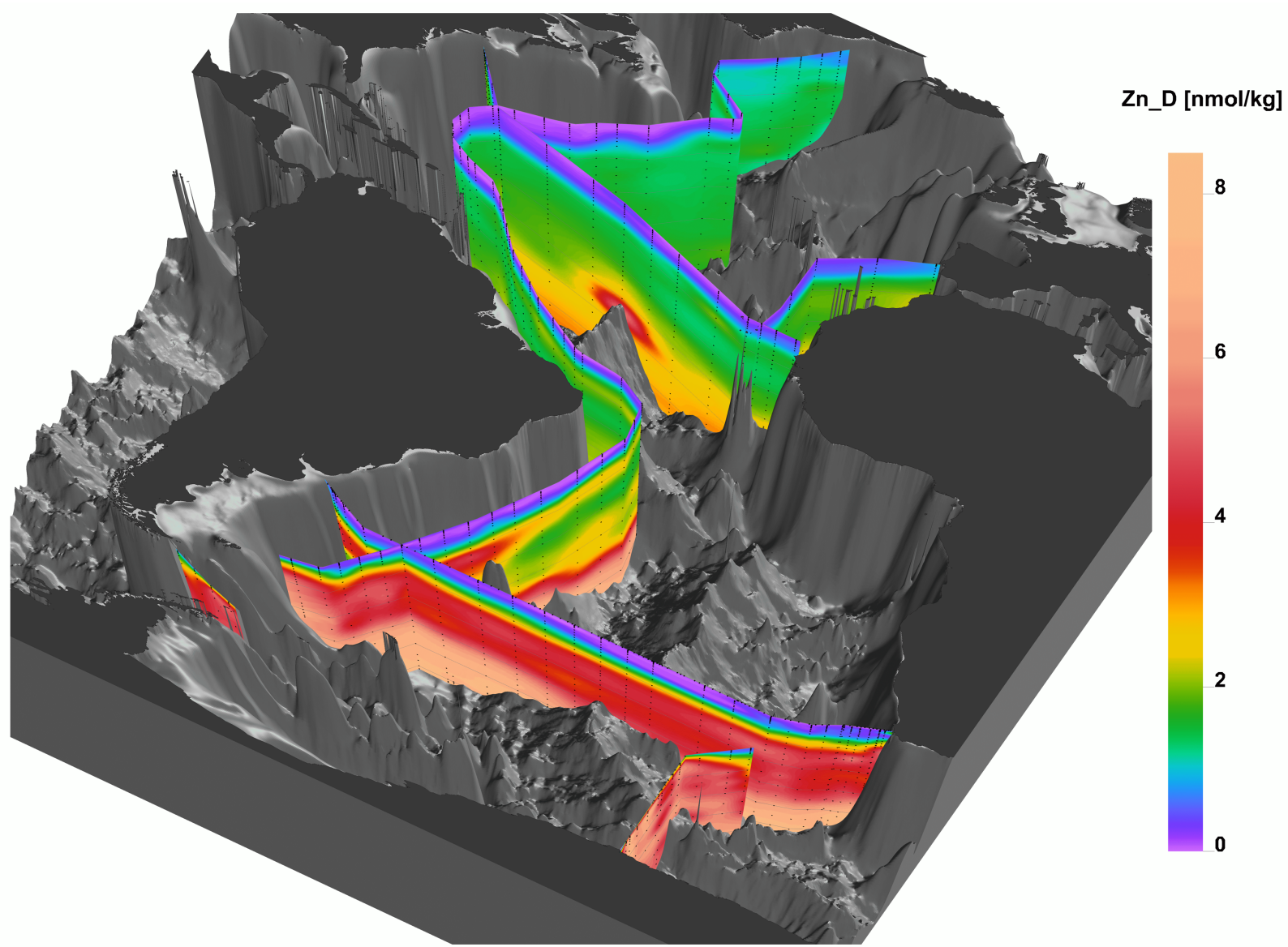

eGEPTRACES Data: Hein J de Baar, Kenneth w Bruland, Tim Conway, Peter Croot, Gideon M Henderson, Seth John,

Figure 14. 3-D image illustrating the dissolved concentration of $\mathrm{Zn}$ in the Atlantic. Data from the 1596 1597 GEOTRACES Intermediate Data Product 2017 [171]. Graphics produced by Reiner Schlitzer for eGEOTRACES [172]. 